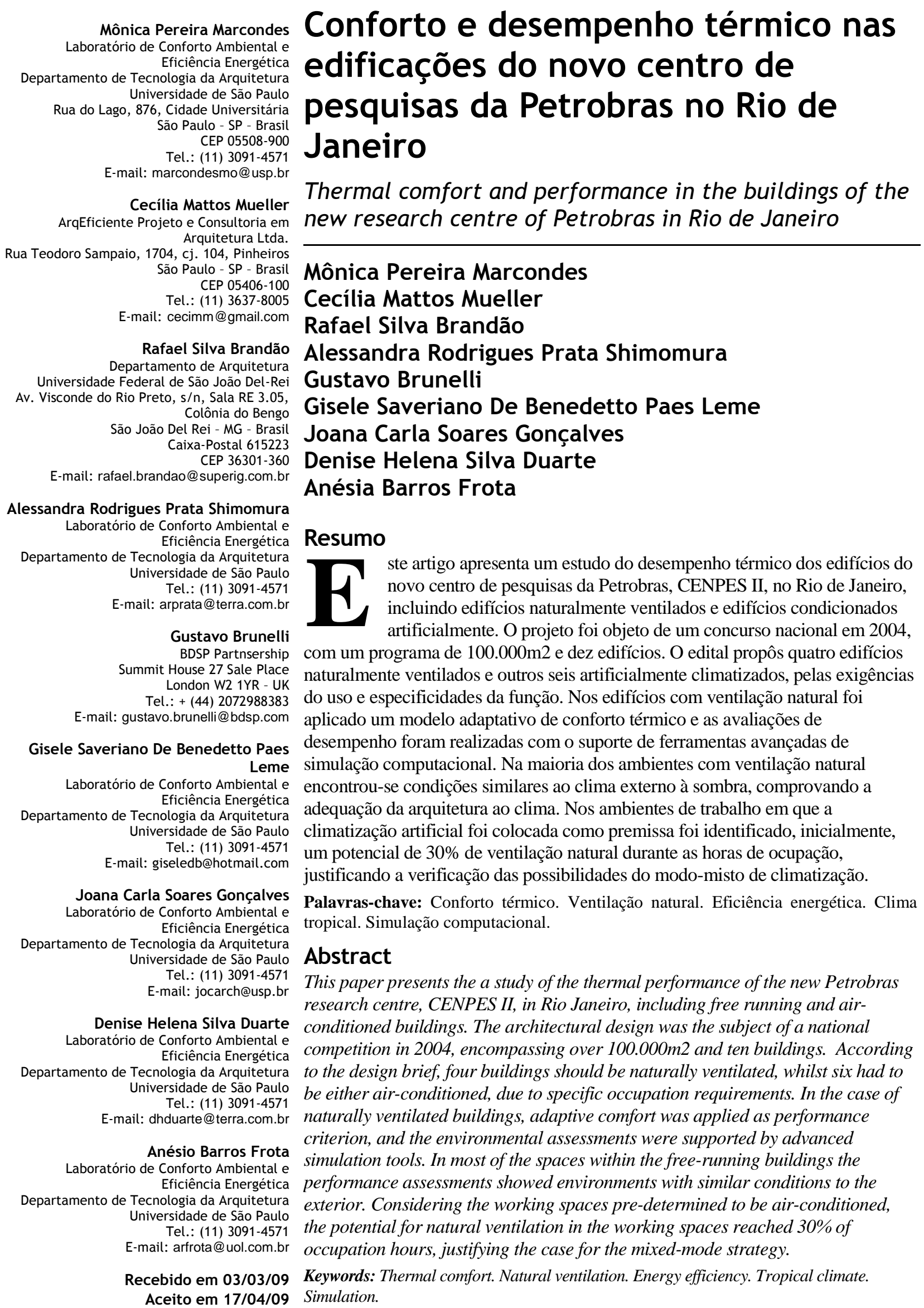

Mônica Pereira Marcondes Laboratório de Conforto Ambiental e Eficiência Energética Departamento de Tecnologia da Arquitetura Universidade de São Paulo Rua do Lago, 876, Cidade Universitária São Paulo - SP - Brasil CEP 05508-900 Tel.: (11) 3091-4571 E-mail: marcondesmo@usp.br

Cecília Mattos Mueller ArqEficiente Projeto e Consultoria em Arquitetura Ltda.

Rua Teodoro Sampaio, 1704, cj. 104, Pinheiros São Paulo - SP - Brasil CEP 05406-100 Tel.: (11) 3637-8005 E-mail: cecimm@gmail.com

Rafael Silva Brandão Departamento de Arquitetura Universidade Federal de São João Del-Rei Av. Visconde do Rio Preto, s/n, Sala RE 3.05, Colônia do Bengo São João Del Rei - MG - Brasil Caixa-Postal 615223 CEP 36301-360

E-mail: rafael.brandao@superig.com.br

Alessandra Rodrigues Prata Shimomura Laboratório de Conforto Ambiental Eficiência Energética Departamento de Tecnologia da Arquitetura Universidade de São Paulo Tel.: (11) 3091-4571 E-mail: arprata@terra.com.br

Gustavo Brunell BDSP Partnsership Summit House 27 Sale Place London W2 1YR - UK

Tel.: + (44) 2072988383

E-mail: gustavo.brunelli@bdsp.com

Gisele Saveriano De Benedetto Paes Leme

Laboratório de Conforto Ambiental e Eficiência Energética

Departamento de Tecnologia da Arquitetura Universidade de São Paulo Tel.: (11) 3091-4571

E-mail: giseledb@hotmail.com

Joana Carla Soares Gonçalves

Laboratório de Conforto Ambiental e Eficiência Energética

Departamento de Tecnologia da Arquitetura

Universidade de São Paulo Tel.: (11) 3091-4571 E-mail: jocarch@usp.br

Denise Helena Silva Duarte Laboratório de Conforto Ambiental e Eficiência Energética Departamento de Tecnologia da Arquitetura

Universidade de São Paulo Tel.: (11) 3091-4571

E-mail: dhduarte@terra.com.br

Anésio Barros Frota Laboratório de Conforto Ambiental e Eficiência Energética Departamento de Tecnologia da Arquitetura Universidade de São Paulo Tel.: (11) 3091-4571

E-mail:arfrota@uol.com.br

Recebido em 03/03/09 Aceito em 17/04/09

\section{Conforto e desempenho térmico nas edificações do novo centro de pesquisas da Petrobras no Rio de Janeiro}

Thermal comfort and performance in the buildings of the new research centre of Petrobras in Rio de Janeiro

\author{
Mônica Pereira Marcondes \\ Cecília Mattos Mueller \\ Alessandra Rodrigues Prata Shimomura \\ Gustavo Brunelli \\ Gisele Saveriano De Benedetto Paes Leme \\ Joana Carla Soares Gonçalves \\ Denise Helena Silva Duarte \\ Anésia Barros Frota
}

Rafael Silva Brandão

ste artigo apresenta um estudo do desempenho térmico dos edifícios do novo centro de pesquisas da Petrobras, CENPES II, no Rio de Janeiro, incluindo edifícios naturalmente ventilados e edifícios condicionados artificialmente. O projeto foi objeto de um concurso nacional em 2004, com um programa de $100.000 \mathrm{~m} 2$ e dez edifícios. O edital propôs quatro edifícios naturalmente ventilados e outros seis artificialmente climatizados, pelas exigências do uso e especificidades da função. Nos edifícios com ventilação natural foi aplicado um modelo adaptativo de conforto térmico e as avaliações de desempenho foram realizadas com o suporte de ferramentas avançadas de simulação computacional. Na maioria dos ambientes com ventilação natural encontrou-se condições similares ao clima externo à sombra, comprovando a adequação da arquitetura ao clima. Nos ambientes de trabalho em que a climatização artificial foi colocada como premissa foi identificado, inicialmente, um potencial de $30 \%$ de ventilação natural durante as horas de ocupação, justificando a verificação das possibilidades do modo-misto de climatização.

Palavras-chave: Conforto térmico. Ventilação natural. Eficiência energética. Clima tropical. Simulação computacional.

\section{Abstract}

This paper presents the a study of the thermal performance of the new Petrobras research centre, CENPES II, in Rio Janeiro, including free running and airconditioned buildings. The architectural design was the subject of a national competition in 2004, encompassing over 100.000m 2 and ten buildings. According to the design brief, four buildings should be naturally ventilated, whilst six had to be either air-conditioned, due to specific occupation requirements. In the case of naturally ventilated buildings, adaptive comfort was applied as performance criterion, and the environmental assessments were supported by advanced simulation tools. In most of the spaces within the free-running buildings the performance assessments showed environments with similar conditions to the exterior. Considering the working spaces pre-determined to be air-conditioned, the potential for natural ventilation in the working spaces reached $30 \%$ of occupation hours, justifying the case for the mixed-mode strategy.

Keywords: Thermal comfort. Natural ventilation. Energy efficiency. Tropical climate. Simulation. 


\section{Introdução}

Este trabalho trata do desempenho térmico dos edifícios do novo centro de pesquisas da Petrobras no Rio de Janeiro, CENPES II, localizado às margens da Baía de Guanabara, na Ilha do Fundão.

O projeto foi objeto de um concurso nacional em 2004. A proposta vencedora foi a da equipe Zanettini Arquitetura S.A., com co-autoria de José Wagner Garcia (Fgura 1). O complexo cobre cerca de $100.000 \mathrm{~m}^{2}$ de área construída (Figura 2), com o objetivo de complementar as instalações do centro de pesquisas existente, CENPES I, com laboratórios, escritórios, um centro de convenções e edifícios de apoio.

O edital impôs medidas em prol do conforto ambiental, da eficiência energética e outras ligadas ao impacto ambiental da construção e à eficiência no consumo de água e energia. Essas medidas são: 1. Orientação dos edifícios de acordo com o impacto da radiação solar, 2. Forma arquitetônica de acordo com os princípios da arquitetura bioclimática, 3. Uso apropriado dos materiais de acordo com as condições climáticas, 4. Proporção das áreas envidraçadas de fachada a fim de minimizar os ganhos térmicos e maximizar o aproveitamento da luz natural, 5. Proteções solares, 6. Ventilação natural, 7. Luz natural, 8. Cuidado com o impacto ambiental dos materiais, 9. Uso racional da água, coleta de água de chuva e aproveitamento de águas cinzas, 10. Uso da vegetação para a qualidade ambiental do conjunto.
O interesse da Petrobras pelas questões ambientais levou à busca pela certificação LEED, Leadership in Environmental and Energy Design, o que trouxe mais uma série de requisitos para o projeto. Para a elaboração dos aspectos ambientais do edital e a seleção do projeto, a Petrobras contou com pesquisadores do Laboratório de Eficiência Energética em Edificações, LabEEE, e do Laboratório de Conforto Ambiental, LabCon, ambos da Universidade Federal de Santa Catarina, e da Escola Politécnica da Universidade de São Paulo.

O projeto vencedor foi fortemente influenciado pela arquitetura bioclimática carioca. A implantação mostra uma composição predominantemente horizontal, com os principais edifícios orientados sobre os eixos norte-sul e leste-oeste (Figura 3), e os espaços de transição têm um papel fundamental na qualidade ambiental do projeto.

O processo de projeto foi guiado por avaliações de desempenho ambiental desde o estágio conceitual, executadas pelo Laboratório de Conforto Ambiental e Eficiência Energética (LABAUT) do Departamento de Tecnologia, da Faculdade de Arquitetura e Urbanismo da Universidade de São Paulo, (FAUUSP). Além de influenciar a arquitetura, os estudos de desempenho ambiental contribuíram também para os projetos de paisagismo, sistemas de climatização e iluminação artificial.

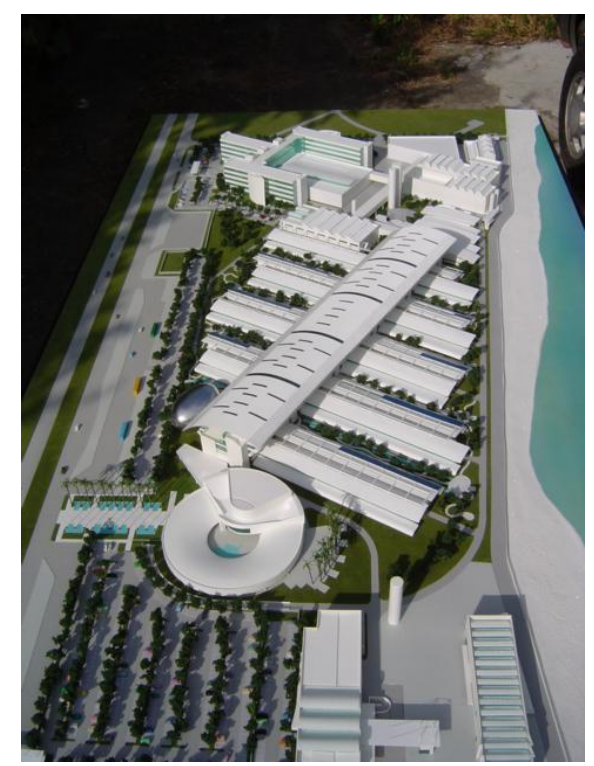

Fonte: Zanettini Arquitetura (imagem cedida).

Figura 1 - Modelo físico do CENPES II, visto do Sudeste

8 Marcondes, M. P.; Mueller, C. M.; Brandão, R. S. B.; Shimomura, A. R. P.; Brunelli, G.; Paes Leme, G. S. De

B.; Gonçalves, J. C. S.; Duarte, D. H. S.; Frota, A. B. 


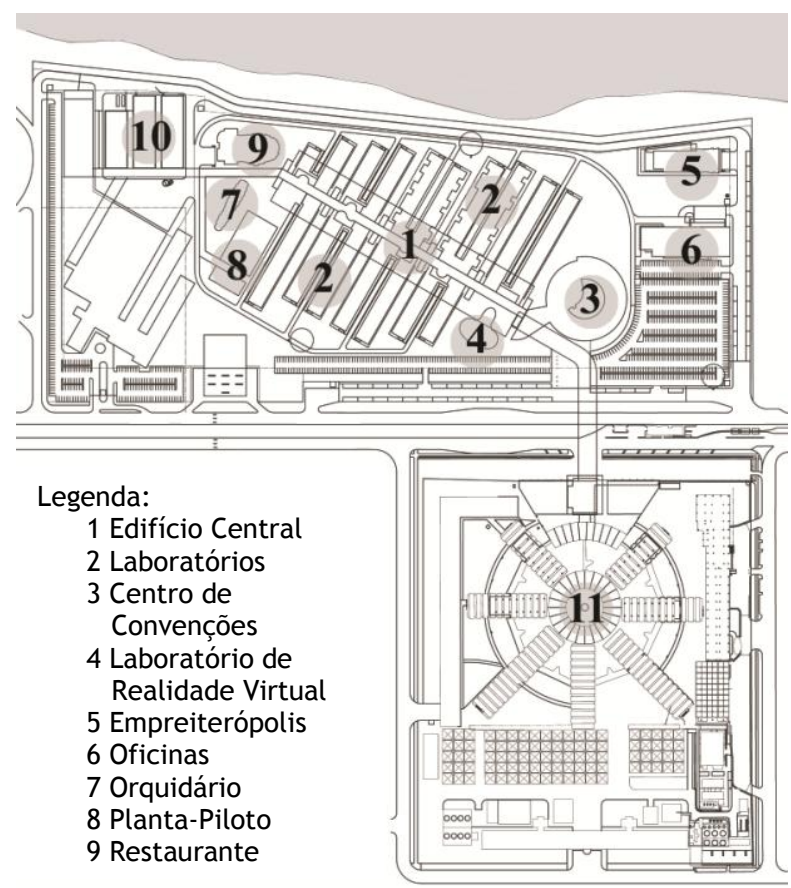

Figura 2 - Implantação do CENPES II

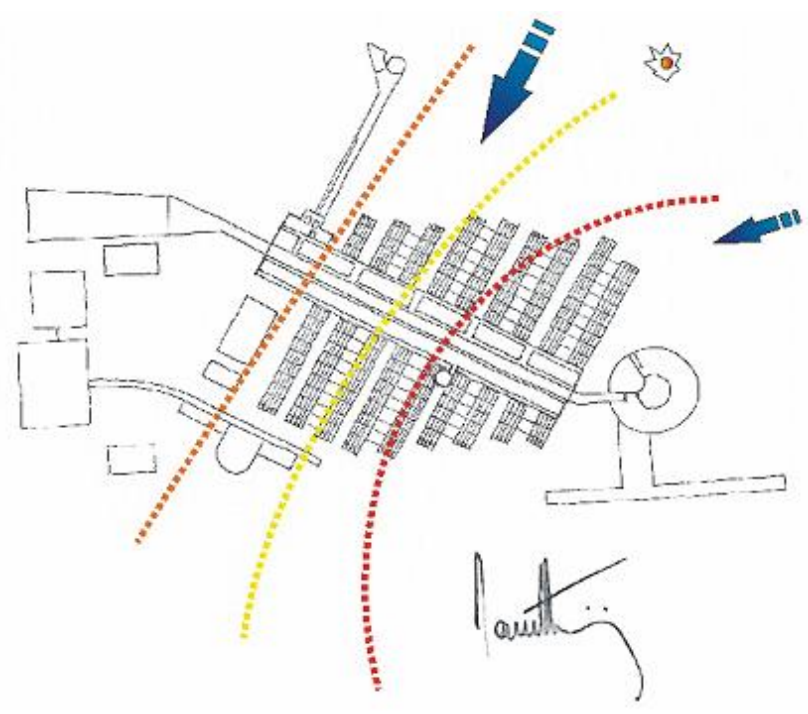

Figura 3 - Croqui do arquiteto, destacando os edifícios principais da composição arquitetônica

De acordo com o programa de necessidades, quatro dos dez edifícios foram projetados para que a maioria de seus ambientes fosse ventilada naturalmente: Empreiteirópolis (edifício de pessoal e manutenção), Planta-Piloto (edifício de pesquisa), Oficinas (edifício de construção de modelos físicos) e Central de Utilidades (edifício de entrada dos sistemas municipais de utilidades, incluindo água, energia elétrica, uma central de geração de energia e utilidades para os laboratórios).

Os outros seis foram planejados para serem parcialmente ou completamente condicionados artificialmente: Laboratórios, Prédio Central (escritórios), Centro de Convenções, Centro de Realidade Virtual, Restaurante e Orquidário.

\section{Método para avaliação de desempenho térmico}

\section{Considerações metodológicas}

Trabalhando com a arquitetura desde os estágios iniciais, tinha-se por objetivo fornecer parâmetros e diretrizes de desempenho térmico e energético que pudessem ser incorporados ao desenho dos 
edifícios, e não apenas verificar o desempenho $a$ posteriori.

Não havia, ainda, durante o desenvolvimento do trabalho, em 2004 e 2005, parâmetros préestabelecidos para o nível de desempenho energético desejado para as edificações brasileiras. Do mesmo modo, não havia um valor mínimo para o número de horas em conforto para edifícios com condicionamento natural. Por isso, os estudos basearam-se principalmente em análises comparativas de alternativas de projeto, avaliandose o impacto de alterações arquitetônicas no desempenho térmico e na carga térmica resultante.

O desempenho térmico foi avaliado na seguinte seqüência:

(a) construção de uma base climática horária anual a partir de dados da estação meteorológica do Aeroporto Internacional Tom Jobim ${ }^{1}$, com dados de 1998 a 2004 (METAR, 2005). A radiação solar foi estimada com o Meteonorm (METEOTEST, 2003);

(b) identificação do período crítico (mês com a temperatura média mais alta, fevereiro de 2003) e um dia estável desse mês (09/02) com o objetivo de realizar estudos específicos de carga térmica máxima e fluxo de calor pela envoltória.;

(c) estabelecimento de parâmetros de conforto para espaços condicionados naturalmente e artificialmente;

(d) estudos preliminares para a seleção de ambientes críticos, zoneamento térmico, esquemas de ocupação, materiais e cargas internas;

(e) simulação de dinâmica de fluidos para estabelecer fluxos de ar ao redor dos edifícios, coeficientes de pressão, velocidades nas aberturas e coeficientes de troca de calor por convecção;

(f) simulação termodinâmica dos edifícios, sem considerar o condicionamento artificial, para determinar potencialmente o número de horas em conforto;

(g) especificação dos parâmetros de modo misto para ambientes onde o edital requeria o uso de condicionamento artificial ou com potencial insuficiente para uso de ventilação natural;

(h) simulação das estratégias de ventilação natural, de modo misto e dos ambientes condicionados artificialmente; e

\footnotetext{
${ }^{1}$ Dados gentilmente cedidos pelo Laboratório de Meteorologia Aplicada a Sistemas de Tempo Regionais do Instituto de Astronomia, Geofísica e Ciências Atmosféricas da Universidade de São Paulo (MASTER/IAG/USP).
}

(i) avaliação dos resultados e propostas de mudanças nas características arquitetônicas, materiais e critérios de operação dos edifícios.

\section{Parâmetros de conforto}

\section{Conceituação e referências teóricas}

Para as condições ambientais de espaços de trabalho no Brasil são duas as referências: NR 15 (BRASIL, 1978) e NR 17 (BRASIL, 1973). A primeira refere-se principalmente a ambientes de calor extremo, tais como indústrias, e recomenda períodos de descanso em função do tempo de exposição a temperaturas acima de um valor determinado, enquanto a segunda afirma apenas que $o$ ambiente deve ser adequado às características psico-fisiológicas dos trabalhadores e à natureza da tarefa. Para ambientes em que há demanda intelectual e necessidade de atenção constante, a NR 17 recomenda os seguintes parâmetros: temperatura efetiva entre $20^{\circ} \mathrm{C}$ e $23^{\circ} \mathrm{C}$, umidade relativa do ar não inferior a $40 \%$ e velocidade do ar não superior a 0,75 m/s.

Nesse projeto, a NR 15 não se aplicaria aos edifícios com condicionamento artificial parcial ou total, já que não há espaços com geração extrema de calor. No caso da NR 17, embora ela se aplique teoricamente a todos os ambientes no complexo, seria impossível atender os seus parâmetros sem a utilização de condicionamento artificial, nas condições climáticas locais.

Para ambientes condicionados artificialmente, existem ainda mais duas referências: a NBR 6401 (ABNT, 1980) e a Orientação Técnica sobre Padrões Referenciais de Qualidade do Ar Interior (ANVISA, 2003). Em ambos os casos, os intervalos recomendados para temperatura de bulbo seco (TBS) e umidade relativa do ar (UR) são: TBS $=23-26^{\circ} \mathrm{C}$ e UR $=40-65 \%$; $\mathrm{TBS}_{\max }=$ $26,5-27{ }^{\circ} \mathrm{C}$ e $\mathrm{UR}_{\max }=65 \%$; $\mathrm{TBS}_{\max }=28{ }^{\circ} \mathrm{C} \mathrm{e}$ $\mathrm{UR}=70 \%$ (para áreas de acesso). Considerando a velocidade do ar a $1,5 \mathrm{~m}\left(\mathrm{v}_{\mathrm{a} .1,5 \mathrm{~m}}\right)$ de 0,025 a 0,25 $\mathrm{m} / \mathrm{s}$.

Também foram utilizadas duas referências internacionais: ISO 7730 (1994) e ASHRAE-55 $(1992)^{2}$. A primeira estima o Percentual de Pessoas Insatisfeitas (PPD) em um dado ambiente e recomenda valores inferiores a 10-15\%. No entanto, tais parâmetros limitam-se às seguintes condições: TBS entre $10^{\circ} \mathrm{C}$ e $30^{\circ} \mathrm{C}$, UR entre $30 \%$ e $70 \%$ e velocidade do ar abaixo de $1 \mathrm{~m} / \mathrm{s}$. Por sua

\footnotetext{
${ }^{2}$ No início do desenvolvimento do projeto (2004), a versão corrente da ASHRAE 55 datava de 1992. A versão atual, incluindo o conceito de modelo adaptativo, foi publicada oficialmente durante o andamento do projeto.
} 
vez, a segunda estabelece zonas de conforto diferenciadas para verão e inverno, permitindo um PPD de 20\%, mais apropriado para as condições locais. A zona de conforto da ASHRAE 55 (1992) é dada por temperatura operativa (to) e umidade relativa do ar (UR), como segue: no inverno, de 20 a $23,5^{\circ} \mathrm{C}$ e $60 \%$ UR, correspondendo à temperatura efetiva de 20 e $23,5^{\circ} \mathrm{C}$ (ET*); no verão, de 22,5 a $26^{\circ} \mathrm{C}$, também com $60 \%$ UR, correspondendo à temperatura efetiva de 23 e $26^{\circ} \mathrm{C}$, e a velocidade do ar nunca deve ser superior a $0,8 \mathrm{~m} / \mathrm{s}$.

No entanto, a aplicação dessas normas internacionais a edifícios naturalmente ventilados ou com sistemas mistos de condicionamento ainda era discutível. Os limites de temperatura e umidade para a aplicação das mesmas descartavam sua utilização para situações de calor e alta umidade.

De Dear, Bragger e Cooper (1997) discutiram o assunto no relatório ASHRAE RP-884 (2004), baseado em um experimento com 20.700 ocupantes de 160 edifícios em 9 países dentre eles Estados Unidos, Inglaterra, Tailândia e Indonésia. O resultado indica que ocupantes de edifícios naturalmente ventilados apresentam maiores tolerâncias à variação das condições térmicas internas, fato não contemplado nas adaptações do modelo de Fanger (1970) utilizadas na ASHRAE 55 e ISO 7730 (ISSO, 1994). O relatório propõe um índice de conforto adaptativo, apresentando um modelo empírico que incorpora questões como aclimatação, vestuário, comportamento e tolerância a variações climáticas.

Nesse índice, o conforto interno é função das condições externas médias. $\mathrm{O}$ modelo é baseado na Nova Temperatura Efetiva (ET*), definida como a to de um ambiente a $50 \%$ UR, que causaria as mesmas trocas de calor sensível e latente que as experimentadas pelo usuário no ambiente em estudo. A temperatura neutra (tn), que define a zona de conforto, é determinada a partir da ET* média mensal e varia de acordo com o clima local e com a época do ano. Desse modo, ao invés das regulamentações existentes até então, foi explorada a possibilidade de se utilizar o modelo adaptativo, com o objetivo de ampliar os períodos de ventilação natural e testar o modo misto.

\section{Parâmetros de desempenho térmico para ambientes condicionados artificialmente}

Os parâmetros para os edifícios condicionados artificialmente foram determinados pela ISO 7730 e normas correlatas (ISO 7726, 1998; ISO 8996, 1990; ISO 9920, 1995), e confrontados com as referências nacionais. Estudos exploratórios determinaram arranjos de TBS, UR e $v_{a}$ que produzissem um PPD < 10\%, assumindo-se:

(a) taxa metabólica (M) para atividade sedentária (ISO 8996): $\mathrm{M}=70 \mathrm{~W} / \mathrm{m}^{2}$ (1,2 met);

(b) resistência térmica da roupa $\mathrm{I}_{\text {clo }}$ (ISO 9920) de 0,5 clo (camisa de manga curta, calças leves, roupa de baixo, meias e sapatos);

(c) TRM = TBS, já que os fechamentos são sombreados e/ou isolados. Desse modo (ISO 7726), to = TBS; $\mathrm{e}$

(d) va $<0,25 \mathrm{~m} / \mathrm{s}$ para atividades leves ou sedentárias durante o verão, se a to $<26^{\circ} \mathrm{C}$ (ISO 7730; ASHRAE 55). Acima disso, a velocidade do ar deve ser inferior a $0,8 \mathrm{~m} / \mathrm{s}$.

Os resultados para os estudos exploratórios são mostrados na Tabela 1 .

Com base nos cenários propostos, foi recomendado que o ar condicionado funcionasse com TBS $=26^{\circ} \mathrm{C} ;$ UR $=65 \%$ e $v_{a}=0,1 \mathrm{~m} / \mathrm{s}$, o que atenderia a ISO 7730 e as referências nacionais, mas que resultaria em temperaturas mais altas se comparadas às usualmente adotadas na prática brasileira. Foram então realizadas simulações exploratórias para se determinar a redução nas cargas térmicas e conseqüente impacto no consumo de energia em função do ar condicionado. As simulações finais para cargas térmicas anuais, no entanto, foram realizadas considerando-se condições internas de $24^{\circ} \mathrm{C}$ e $50 \%$ UR, conforme determinação da equipe de engenharia, e a carga térmica para o dimensionamento do sistema foi calculada considerando-se os ambientes internos a $22^{\circ} \mathrm{C}$ e $50 \%$ UR.

\begin{tabular}{l|c|c}
\hline $\mathbf{v}_{\mathbf{a}}$ & UR & TBS \\
\hline $\mathbf{0 , 1 m} / \mathbf{s}$ & $50 \%$ & $26,4^{\circ} \mathrm{C}$ \\
\hline & $65 \%$ & $26,0^{\circ} \mathrm{C}$ \\
\hline $\mathbf{0 , 2} \mathbf{m} / \mathbf{s}$ & $50 \%$ & $27,0^{\circ} \mathrm{C}$ \\
\hline & $65 \%$ & $26,6{ }^{\circ} \mathrm{C}$ \\
\hline $\mathbf{0 , 5 m} / \mathbf{s}$ & $50 \%$ & $27,8^{\circ} \mathrm{C}$ \\
\hline & $65 \%$ & $27,5^{\circ} \mathrm{C}$ \\
\hline $\mathbf{0 , 8 m} / \mathbf{s}$ & $50 \%$ & $28,3{ }^{\circ} \mathrm{C}$ \\
\hline & $65 \%$ & $27,9^{\circ} \mathrm{C}$ \\
\hline
\end{tabular}

Tabela 1 - Combinação de UR e TBS para PPD $\leq 10 \%$, considerando-se $M=70 \mathrm{~W} / \mathrm{m}^{2}, \mathrm{I}_{\mathrm{clo}}=0,5 \mathrm{clo}, \mathrm{t}_{\mathrm{o}}=$ TBS 


\section{Parâmetros de desempenho térmico para} ambientes naturalmente ventilados

Para edifícios naturalmente ventilados, foi utilizado o modelo proposto no ASHRAE RP-884, que estabelece que a tn está relacionada à temperatura externa a partir da Temperatura Efetiva Externa Média (meET*), de acordo com a equação (1):

$\mathrm{t}_{\mathrm{n}}=18,9+0,255 \cdot \operatorname{meET}^{*}$

A ET* é calculada a partir de uma adaptação do método proposto por Szokolay (2001). Assumindo-se valores de to $=$ tbs, a ET* é calculada para cada hora do banco de dados climáticos anual. Na sequência, tn é calculada usando a $\mathrm{ET}^{*}$ média para as últimas 720 horas (30 dias). A tabela 2 mostra as faixas de conforto para $\mathrm{PPD} \leq 10 \%$, com variações de temperatura entre $\left(\mathrm{t}_{\mathrm{c}}-2.5^{\circ} \mathrm{C}\right)$ e $\left(\mathrm{t}_{\mathrm{c}}+2.5^{\circ} \mathrm{C}\right)$, (Figura 4$)$
Para ambientes naturalmente ventilados, os valores de TBS, UR e TRM (temperatura radiante média) são utilizados para se calcular a Temperatura Efetiva para cada hora, que é então comparada à temperatura de conforto e então classificada como "Confortável", "Quente" ou "Fria". Já os ambientes com ar condicionado foram avaliados com base nas suas cargas térmicas anuais e máximas.

Calculando-se ET* a partir de TBS e UR para cada hora da base climática e comparando-se com a temperatura da zona de conforto, observa-se que $50 \%$ do tempo de ocupação apresenta condições de conforto térmico (Tabela 2).

Ou seja, em uma situação hipotética, em que as condições internas fossem equivalentes aos valores calculados da ET*, obter-se-ia conforto em $50 \%$ do tempo de ocupação, o que passou a ser referência para o desempenho de ambientes naturalmente ventilados.

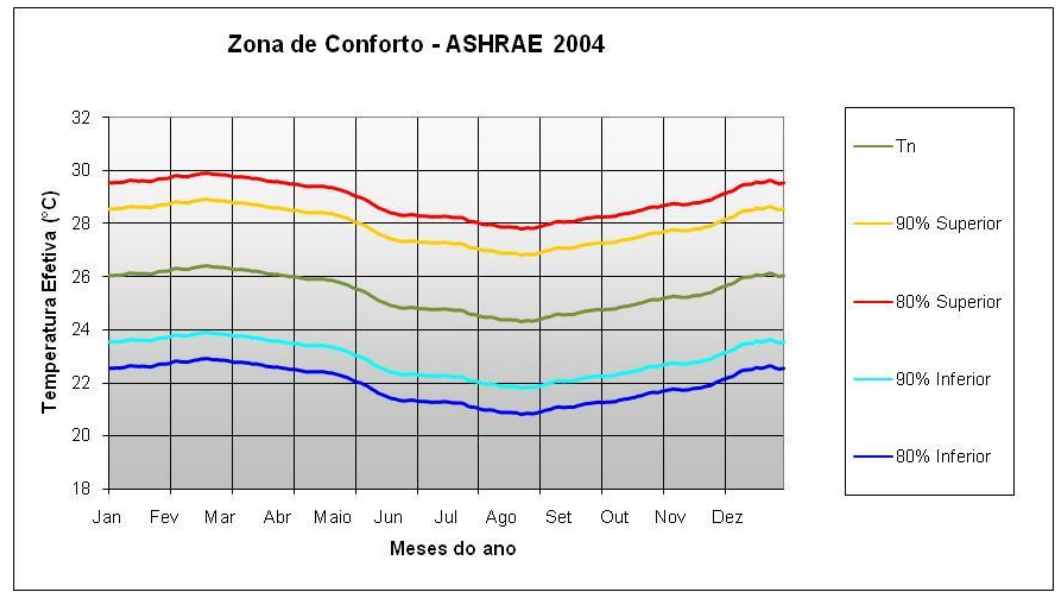

Figura 4 - Zona de conforto térmico para $90 \%$ e $80 \%$ de pessoas satisfeitas

\begin{tabular}{l|c|c|r}
\hline Mês & Frio & Conforto & Quente \\
\hline Janeiro & $0.2 \%$ & $31.5 \%$ & $68.2 \%$ \\
\hline Fevereiro & $0.0 \%$ & $23.9 \%$ & $76.1 \%$ \\
\hline Março & $0.5 \%$ & $35.7 \%$ & $63.8 \%$ \\
\hline Abril & $0.5 \%$ & $35.7 \%$ & $63.8 \%$ \\
\hline Maio & $2.6 \%$ & $44.6 \%$ & $52.8 \%$ \\
\hline Junho & $22.1 \%$ & $71.5 \%$ & $6.5 \%$ \\
\hline Julho & $23.6 \%$ & $69.5 \%$ & $6.9 \%$ \\
\hline Agosto & $41.9 \%$ & $56.3 \%$ & $1.7 \%$ \\
\hline Setembro & $20.5 \%$ & $69.2 \%$ & $10.3 \%$ \\
\hline Outubro & $5.2 \%$ & $71.7 \%$ & $23.1 \%$ \\
\hline Novembro & $4.6 \%$ & $46.7 \%$ & $48.7 \%$ \\
\hline Dezembro & $0.2 \%$ & $39.5 \%$ & $60.3 \%$ \\
\hline Ano & $\mathbf{1 2 . 4 \%}$ & $\mathbf{5 2 . 5 \%}$ & $\mathbf{3 5 . 0 \%}$ \\
\hline
\end{tabular}

Tabela 2 - Aplicação do índice de conforto a um ambiente com to e UR iguais ao ar externo: frequiência de ocorrência das horas em conforto entre $6 \mathrm{~h}$ e $18 \mathrm{~h}$ 


\section{Parâmetros de desempenho para a estratégia de modo misto de condicionamento}

A experiência européia em projetos recentes indica que ambientes internos com um mínimo de $30 \%$ do período de ocupação em conforto sem a necessidade de condicionamento artificial poderiam ser operados em modo misto de condicionamento $^{3}$.

A abordagem contemporânea do modo misto é nova no Brasil. Ainda hoje a maior parte dos edifícios condicionados artificialmente é de caixas seladas, com pisos elevados e forros isolados. A opção pelo ar condicionado central, combinada com a operação automatizada das janelas para viabilizar a ventilação natural em certos períodos do ano não é considerada na arquitetura comercial, por razões técnicas e econômicas.

Ainda assim, acredita-se que o modo misto traz vantagens econômicas e ambientais, ao reduzir o período de condicionamento artificial e permitir variações aceitáveis das condições ambientais internas, dentro dos limites da zona de conforto. Isso também aumenta a interação do usuário com o ambiente exterior, o que se provou ter efeitos psicológicos benéficos (HOPPE, 2002). Além disso, o modo misto resulta em reduções das cargas térmicas ao longo dos períodos de condicionamento artificial, já que a ventilação natural evita o acúmulo de calor, especialmente durante a noite. Por essa razão, a ventilação noturna foi recomendada mesmo em ambientes totalmente condicionados artificialmente durante o período de ocupação.

Nesse projeto, nos edifícios com ar condicionado, o modo misto foi descartado de início somente nos Laboratórios, no auditório do Centro de Convenções e no Centro de Realidade Virtual, que necessitavam de um controle mais restrito. Nos demais, a estratégia consistia na abertura de janelas a partir de uma TBS interna de $20^{\circ} \mathrm{C}$, permitindo um aumento gradual da taxa de ventilação natural a partir desse valor. Quando a TBS excedia $26^{\circ} \mathrm{C}$, todas as janelas eram fechadas e o sistema de ar condicionado era acionado, mantendo-se a temperatura de $26^{\circ} \mathrm{C}$ ou reduzindo-a para $24^{\circ} \mathrm{C}$ (de acordo com o critério de conforto estabelecido para cada ocupação). Já que velocidades do ar internas superiores a $0,8 \mathrm{~m} / \mathrm{s}$ podem causar desconforto nos ambientes de trabalho, as janelas eram fechadas quando a velocidade do vento externo era superior a $5,0 \mathrm{~m} / \mathrm{s}$, que correspondia a um limite para velocidades internas aceitáveis.

\footnotetext{
${ }^{3}$ Este valor é baseado em avaliações de custo-benefício para a condição européia, já que ainda não há análises para climas tropicais ou para a realidade brasileira.
}

\section{Procedimentos de simulação e método de avaliação}

A determinação do desempenho térmico dos edifícios, incluindo o potencial de ventilação natural e a carga térmica nos períodos condicionados artificialmente, foi feita a partir de simulações computacionais de termodinâmica no $T A S$. Esse programa foi validado pela Secretaria de Estado do Reino Unido como modelo para o cálculo do desempenho energético segundo a regulamentação 17A do "Building Regulations 2000" (UK, 2000). Além disso, o TAS tem sido uma importante ferramenta de estudos de desempenho ambiental de edifícios em instituições de ensino e pesquisa na Europa e utilizado para alguns dos principais projetos de arquitetura aclamados como sustentáveis desde o início da década de 1990, como a sede do Commerzbank em Frankfurt, o edifício da Swiss Re em Londres e a Assembléia Nacional do País de Gales (GONÇALVES, 2003).

O programa utiliza o método dos "Fatores de Resposta Térmica" para o cálculo das trocas térmicas transientes no edifício, ou seja, a resposta do cálculo horário de cada "nó" ou ponto da rede é considerada para o cálculo dos demais e para o cálculo do momento seguinte. Para o cálculo da ventilação natural, o TAS cria uma "rede de nós" entre as aberturas do modelo e simula todas as zonas a serem analisadas simultaneamente, através de um balanço de energia e massa.

A combinação dos dados climáticos com os coeficientes de pressão fornecidos pelo programa permite o cálculo da variação na pressão exercida pelo vento em todas as aberturas externas e, portanto, as taxas de ventilação por ação dos ventos e suas direções são calculados para cada hora. O efeito chaminé também é integrado à análise. É possível, ainda, simular a interação entre ventilação natural e mecânica.

Para a modelagem geométrica, o TAS possibilita o dimensionamento e o posicionamento detalhado de cada abertura, bem como o controle de operação das mesmas com diferentes funcionamentos ao longo do dia, variando de acordo com as condições climáticas externas e/ou internas. Além disso, permite a simulação em modo misto de condicionamento, realizando a interação entre os modos artificial e natural conforme a mesma gama de controles de operação.

Antes da adoção definitiva do TAS, foram realizados estudos comparativos com os programas Energy Plus e Ecotect. A escolha final se deu em função de três razões: 
(a) o modelo utilizado no TAS mostrou-se adequado para a representação dos fenômenos, apesar de simplificações no cálculo de fator de forma que podem ser contornadas durante a modelagem;

(b) apesar da reconhecida capacidade do Energy Plus no tratamento de ambientes condicionados artificialmente (CRAWLEY, 2008), o TAS apresenta ferramentas mais adequadas na especificação do modo misto, na distribuição e no controle das aberturas; e

(c) a equipe de consultoria já contava com membros treinados na utilização do programa e a interface amigável permitiu uma rápida alteração das variáveis de projeto, facilitando a interação com a equipe de arquitetura.

A modelagem foi realizada em dois estágios: características geométricas, e ocupação e materiais. A geometria é informada através de uma interface gráfica de duas dimensões que permite visualizações tridimensionais. A maior parte das decisões em relação à estratégia de simulação deve ser tomada nesse momento, incluindo localização dos elementos construtivos, localização e tipos de aberturas, zoneamento térmico para atribuição de ocupação e tomada de resultados, além das simplificações geométricas a serem adotadas. As diretrizes de modelagem foram:

(a) simplificação da geometria, observando equivalência de cargas térmicas;

(b) elementos construtivos foram determinados considerando-se o tipo de componente e o funcionamento do elemento;

(c) agrupamento de ambientes com características térmicas e de ocupação em uma mesma zona ou grupo de zonas;

(d) ambientes críticos e adjacências foram zoneados separadamente e modelados de maneira mais detalhada;

(e) ambientes condicionados naturalmente, artificialmente ou de maneira mista foram separados em zonas específicas; e

(f) devido a limitações no cálculo do fator de forma das paredes, buscou-se dividir os ambientes em áreas com razão de aspecto próxima de 1 .

A ocupação e os materiais são informados em um segundo estágio, através de uma interface do tipo "drag \& drop". A informação necessária inclui:

(a) arquivo climático, conforme o capítulo Considerações metodológicas ;

(b) calendário e horário para ocupação, atividades e controles. O calendário afeta todo o edifício, enquanto os horários são atribuídos para cada ambiente e/ou atividade;

(c) componentes, proteções solares e esquemas de abertura são atribuídos a cada elemento construtivo definido na fase de modelagem; e

(d) cargas internas e parâmetros de funcionamento do ar condicionado são atribuídos a cada zona ou grupo de zonas. A temperatura do termostato variou ao longo do processo de simulação, de acordo com as recomendações da Petrobras e do projeto dos sistemas prediais.

As simulações térmicas foram complementadas por simulações de ventilação realizadas em um programa de dinâmica de fluidos, o CFX 5.7. A parametrização é complexa, com poucas variáveis assumidas a priori, sendo responsabilidade do usuário a modelagem adequada da situação desejada.

O modelo pode ser confeccionado em qualquer aplicativo CAD e deve conter todos os objetos de interesse e o entorno, além de um volume estanque para representar o domínio fluido.O espaço fluido dentro do domínio é discretizado através de uma malha, definindo-se os pontos e volumes para os quais as equações fundamentais serão resolvidas.

As simulações foram realizadas em duas etapas. Na primeira, foi estudado o conjunto de edifícios, verificando-se o fluxo nos espaços abertos, as interferências entre os edifícios e a distribuição dos coeficientes de pressão. $\mathrm{Na}$ segunda, foram estudados ambientes específicos, com o objetivo de se verificar o campo de vento interno, informar coeficientes de troca por convecção e testar desenhos de aberturas para ventilação. Nesse caso, as temperaturas das superfícies internas foram extraídas dos resultados de simulação termodinâmica e informadas ao modelo, juntamente com os coeficientes de pressão para cada abertura.

A combinação de resultados entre as simulações de maneira interativa permitiu a avaliação comparativa do desempenho térmico e da eficiência energética das diferentes soluções de acordo com os seguintes critérios:

(a) os períodos de conforto obtidos na operação sem condicionamento artificial foram determinados de acordo com o modelo adaptativo previsto no ASHRAE RP-884 (2004), considerando-se um PPD de $10 \%$ e $20 \%$. A percentagem de horas em conforto, assim como horas em desconforto por calor ou frio, foi calculada para cada zona durante o período de ocupação; 
(b) a carga térmica máxima foi determinada pela maior carga térmica obtida no dia de referência de verão para informar o projeto do sistema de ar condicionado. São consideradas apenas as cargas internas, desconsiderando-se as cargas na serpentina devidas à renovação de ar. Deve-se observar que TBS e TBU do dia de referência são compatíveis com as normas brasileiras de arcondicionado e que os valores nos quais as cargas térmicas na simulação anual excedem aqueles nas simulações do dia de referência nunca são maiores do que 5\% do período de ocupação. Desse modo, as recomendações para dimensionamento do ar condicionado seguem as recomendações do dia de referência de verão adotado;

(c) um perfil anual de cargas foi desenhado a partir do cálculo da freqüência de ocorrência (por intervalos e acumulada) das cargas térmicas ao longo do ano; e

(d) o perfil de ganhos e perdas para os ambientes selecionados é apresentado também para o dia de referência de verão.

Os resultados para cada opção projetual eram comparados, permitindo a escolha daquela que se apresentasse mais adequada.

\section{Parâmetros de projeto para o sistema de ar condicionado}

\section{Laboratórios}

No ar-condicionado dos Laboratórios, incluindo os gabinetes adjacentes às salas especiais, a TBS de $22^{\circ} \mathrm{C}\left(+/-1{ }^{\circ} \mathrm{C}\right)$ foi adotada como critério de projeto, sem o controle de UR, com $100 \%$ de tomada de ar externo, devido às exigências do uso. Nesse caso, observa-se uma discrepância entre os parâmetros testados nas avaliações de conforto e energia e o projeto do ar condicionado, tendo em vista que os usuários dos laboratórios usarão roupas pesadas. Por outro lado, a eliminação do controle de umidade terá impacto positivo no consumo de energia do sistema.

\section{Prédio Central}

No Prédio Central, a climatização dos escritórios foi prevista com insuflamento pelo piso, favorecido pela planta estreita e pelas fachadas e coberturas sombreadas e isoladas.

A temperatura de projeto foi definida em $24^{\circ} \mathrm{C} \mathrm{(+/-}$ $\left.1{ }^{\circ} \mathrm{C}\right)$, sem o controle direto de umidade. Identificou-se a temperatura de $14^{\circ} \mathrm{C}$ para o insuflamento de ar como adequada para remover a umidade necessária para obtenção das condições de conforto, entre $50 \%$ e $55 \%$ UR. Quanto às tomadas de ar, o sistema de ar-condicionado prevê $30 \%$ de ar fresco conectado a um controle de monitoramento de $\mathrm{CO}_{2}$.

Para a circulação central, que dá acesso aos escritórios, foi projetado um sistema de insuflamento de ar a $20^{\circ} \mathrm{C}$, atingindo a altura dos usuários, sem controle específico das condições térmicas, resultando em uma zona de transição entre o ambiente externo e os espaços internos condicionados artificialmente.

\section{Estudo paramétrico peliminar}

Um estudo exploratório foi realizado para se avaliar o potencial para edifícios naturalmente ventilados $\mathrm{e}$ as mudanças no desempenho energético causadas por diferentes condições de operação do sistema de ar condicionado. Para isso, um dos gabinetes (escritórios) existente no edifício de Laboratórios foi simulado. Optou-se por esse ambiente por se tratar de um espaço representativo do complexo, repetido ao longo das fileiras de laboratórios e que permitia a utilização da ventilação natural (Figuras 5 e 6).

O modelo simulado incluía três laboratórios, cada um definido por dois escritórios e uma sala de pesquisa. É um escritório típico, projetado para duas pessoas, com possibilidade de controle pelo usuário dos parâmetros de condicionamento e da abertura das janelas.

$\mathrm{O}$ ambiente conta com uma única interface com o exterior, protegida da radiação solar direta pela circulação externa e por um pavimento técnico superior. Externamente é pintado de branco, seguindo especificações de cor e componentes iguais às aplicadas em outros edifícios do complexo.

Foram avaliadas as orientações norte e sul, com ocupação de $7 \mathrm{~h}$ às $17 \mathrm{~h}$, excluindo finais de semana, de acordo com os horários de trabalho da Petrobras.

\section{Simulações para avaliação do potencial de ventilação natural}

Os resultados iniciais indicaram um potencial para ventilação natural de $13 \%$ a $30 \%$ do período de ocupação. Nos meses mais frios a abertura de $50 \%$ da área de vão levaria ao conforto durante $50 \%$ do tempo. Sendo assim, o modo misto provou-se uma opção válida, especialmente com baixas cargas internas. 


\section{Simulação para avaliação dos parâmetros de condicionamento de ar}

Buscando-se avaliar o potencial para economia de energia em função da operação do sistema de ar condicionado, quatro cenários foram propostos, combinando: $24^{\circ} \mathrm{C}$ com $50 \%$ e $60 \%$ UR e $26^{\circ} \mathrm{C}$ com $60 \%$ e $65 \%$ UR, de $7 \mathrm{~h}$ às $17 \mathrm{~h}$ ).

Com base nos resultados (Figura 7) foi recomendado que o sistema operasse a $26^{\circ} \mathrm{C}$ e
$65 \%$ UR, o que significaria uma redução de $15 \%$ na carga máxima de resfriamento e $30 \%$ na carga máxima de desumidificação, se comparado com o cenário de $24^{\circ} \mathrm{C}$ e $50 \%$ UR. Dada a representatividade dos espaços de trabalho no complexo, essas ações resultariam em uma redução no dimensionamento do sistema, com vantagens ambientais, espaciais e econômicas.

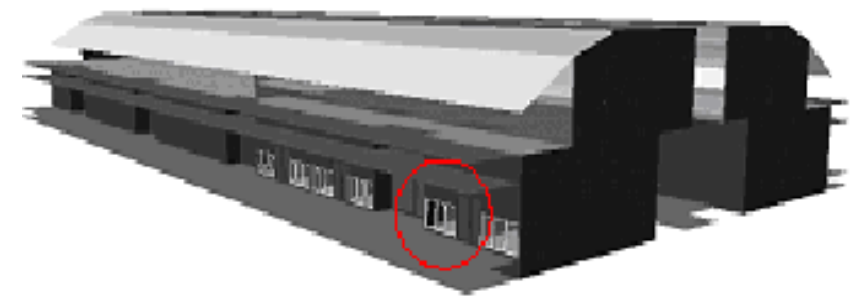

Figura 5 - Modelo de uma fileira de laboratórios, com o primeiro caso de simulação: orientação norte

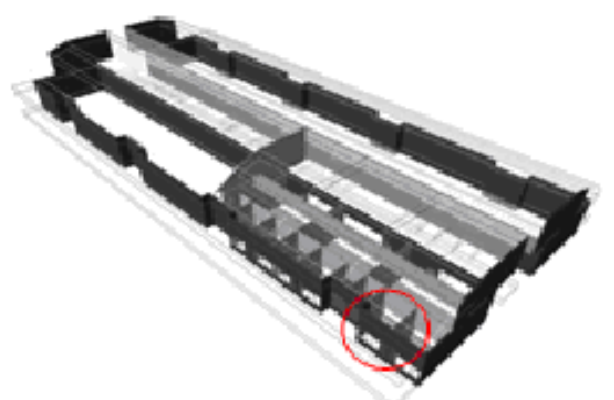

Figura 6 - Modelo de uma fileira de laboratórios, com o primeiro caso de simulação: fechamento lateral oeste

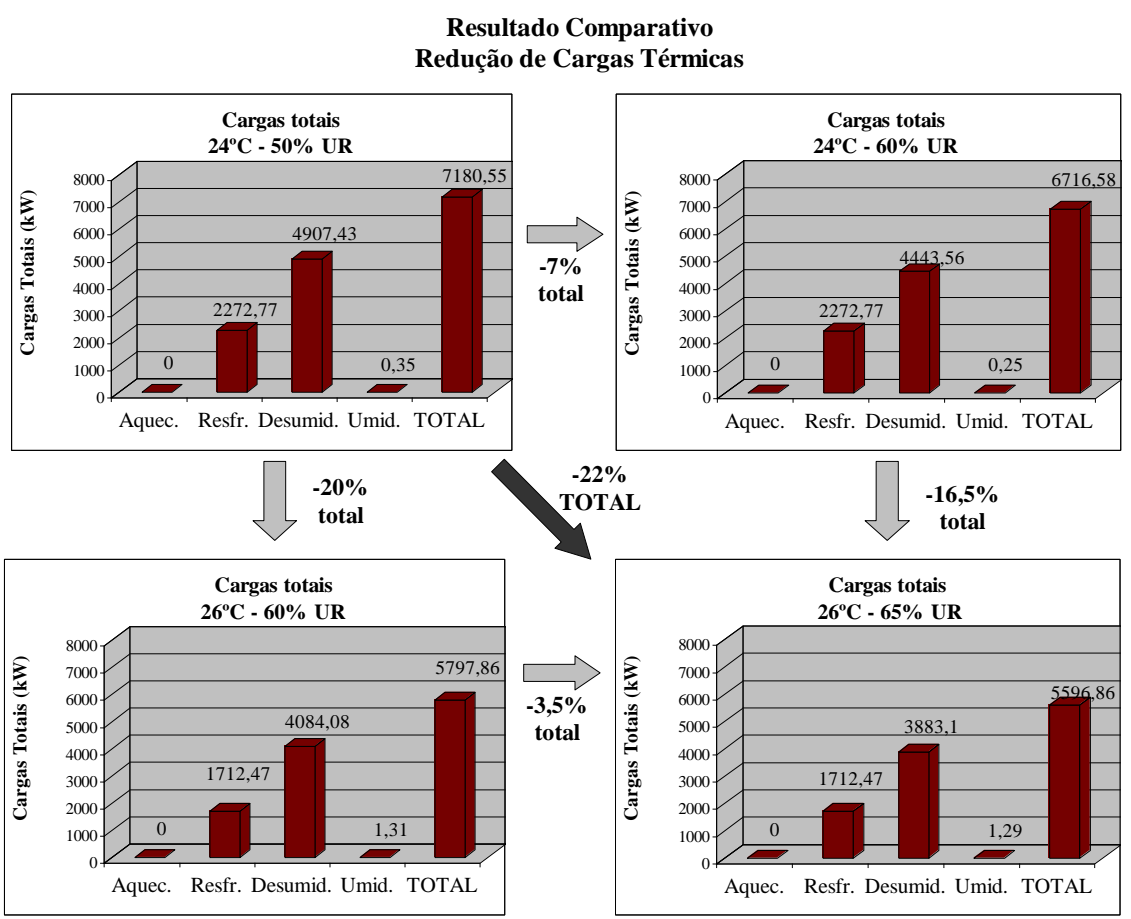

Figura 7 - Resultados de carga térmica para os quatro cenários de operação do ar condicionado

16 Marcondes, M. P.; Mueller, C. M.; Brandão, R. S. B.; Shimomura, A. R. P.; Brunelli, G.; Paes Leme, G. S. De B.; Gonçalves, J. C. S.; Duarte, D. H. S.; Frota, A. B. 


\section{Avaliação de desempenho térmico de ambientes de escritórios}

\section{Gabinetes do edifício de Laboratórios}

Conforme descrito em Estudo paramétrico peliminar, dois gabinetes localizados nas extremidades de uma das fileiras de laboratórios, com orientações norte e sul, foram simulados (Figuras 8 e 9).

\section{$1^{\circ}$ cenário de simulação: análise do potencial da ventilação natural}

De início, simulações foram realizadas para quantificar o potencial de ventilação natural nos gabinetes. Com base nos resultados, mais isolamento térmico foi previsto, conforme solução construtiva acordada com a equipe de arquitetura, especialmente para as paredes internas que separam os escritórios das salas especiais que, devido a requisitos de uso, foram consideradas artificialmente condicionadas a temperaturas mais baixas do que os escritórios adjacentes.

Os resultados das simulações de ventilação natural apontaram a possibilidade de $88 \%$ do total de horas ocupadas no ano dentro da zona de conforto, justificando a introdução do modo-misto. Na sala norte, a porcentagem de horas ocupadas em conforto é de $55,3 \%$, sendo $37,9 \%$ das horas referentes à condição classificada como quente e $6,8 \%$, como frio. Já com relação à sala sul, 88,6\% das horas ocupadas do ano estão em conforto, enquanto que $6,5 \%$ são classificadas como quente e 4,9\% como frio. O melhor desempenho das salas orientadas para sul, em comparação à norte, devese à menor exposição à radiação solar direta, e também à maior exposição das aberturas aos ventos. Outros aspectos positivos foram as cargas internas moderadas e as dimensões reduzidas do ambiente. Ao final, recomendou-se aumentar a massa térmica, no intuito de expandir ainda mais as horas em conforto.

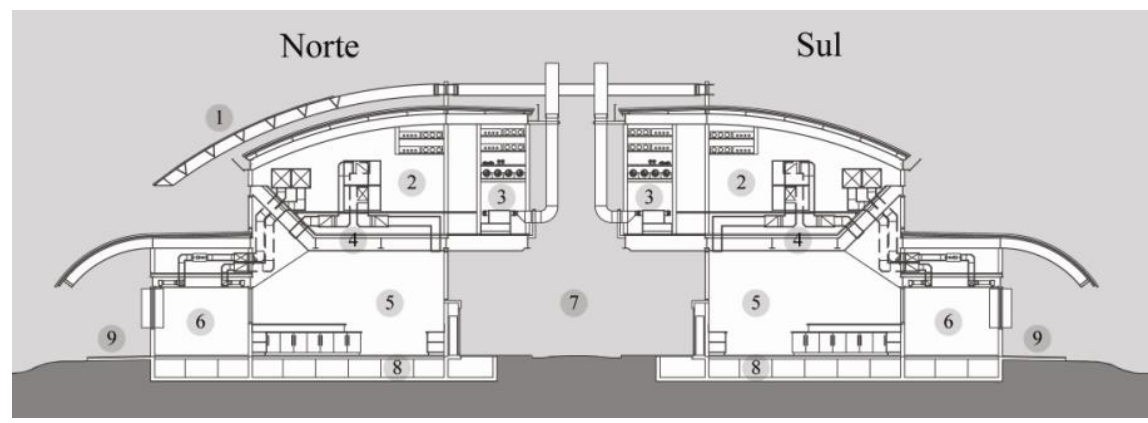

Legenda:

1 Cobertura externa com painéis fotovoltaicos;

2 Pavimento técnico;

3 Pipe-rack;

4 Teto técnico;

5 Sala de laboratório;

6 Gabinete dos pesquisadores;

7 Rua interna de serviços;

8 Piso técnico;

9 Circulação externa aberta.

Figura 8 - Laboratórios: seção transversal indicando os ambientes internos

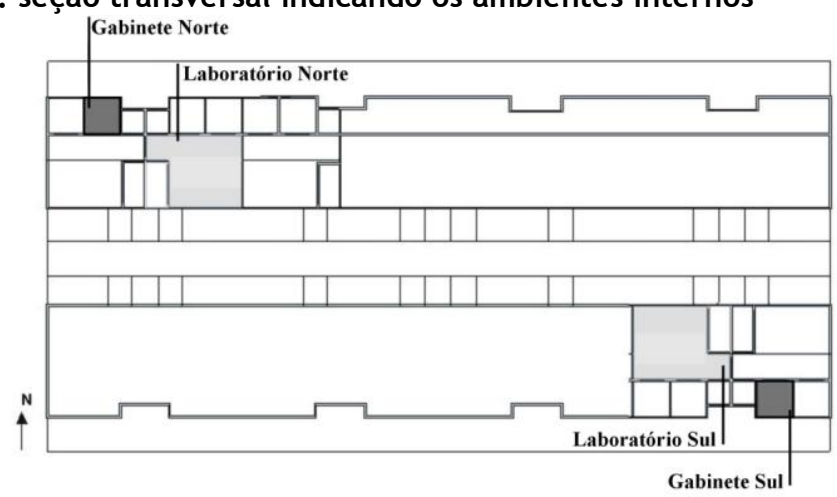

Figura 9 - Localização dos laboratórios e respectivos gabinetes selecionados para a avaliação de desempenho térmico 


\section{$2^{\circ}$ cenário de simulação: análise do modo- misto versus ar condicionado em tempo integral}

Essa etapa visa à eficiência energética comparando o modo-misto com a operação integral de arcondicionado nos gabinetes. $\mathrm{O}$ vão da abertura para ventilação natural correspondeu a $50 \%$ da área total da janela. Sob condições climáticas externas desfavoráveis, as janelas seriam fechadas e o ambiente seria controlado pelo sistema de arcondicionado a $26^{\circ} \mathrm{C}$ e $65 \%$ UR. Nessa etapa, o desempenho do vidro laminado incolor com camada de ar 10+28+6 mm em comparação ao vidro laminado incolor $6 \mathrm{~mm}$ foi testado nas janelas externas.

A introdução do modo-misto causou uma redução de aproximadamente $10 \%$ das cargas totais anuais de ambas as salas, em comparação ao modelo com ar-condicionado integral. Com relação às cargas máximas para o sistema de ar condicionado, foi encontrada uma redução de $30 \%$ para o gabinete norte e de aproximadamente $50 \%$ para o gabinete sul. Com base nesses resultados, o modo-misto foi fortemente recomendado. Seguramente, os resultados seriam melhores se mais massa térmica fosse incorporada.

Por outro lado, os efeitos positivos da $2^{\mathrm{a}}$ camada de vidro durante os períodos de climatização artificial foram irrelevantes, como ilustra a Tabela 3 , devido aos períodos mais longos de ventilação natural.

\section{$3^{\circ}$ cenário de simulação: análise do modo- misto, fase II}

Nessa fase algumas alterações foram propostas pela arquitetura, nas quais as paredes externas e as divisórias seriam substituídas por componentes de menor isolamento térmico.

Durante os períodos de ventilação natural o vão de abertura correspondeu a $80 \%$ da área da janela. Para as horas de ar-condicionado, dois cenários foram comparados em uma base anual: o primeiro com $26^{\circ} \mathrm{C}$ e $65 \%$ UR e o segundo com $24^{\circ} \mathrm{C}$ e $50 \%$ UR. Para o período crítico de verão, dois outros cenários foram testados, com $24^{\circ} \mathrm{C}$ e $50 \%$ UR, e outro com $22^{\circ} \mathrm{C}$ e $50 \%$ UR. Os parâmetros mais baixos de operação do ar-condicionado estudados foram definidos no projeto dos sistemas: $22^{\circ} \mathrm{C}$ e $24^{\circ} \mathrm{C}, 50 \% \mathrm{UR}$. Estes foram então testados contra condições térmicas mais tolerantes, de $26^{\circ} \mathrm{C}$ e $65 \%$ UR.

Com relação ao período de ar-condicionado, o gabinete norte apresentou um melhor desempenho do que o gabinete sul, considerando-se as cargas térmicas máximas (Tabela 5). Esse fato pode ser explicado pela falta de proteção solar na fachada sul, em oposição ao que acontece na fachada norte, protegida pelo beiral da cobertura. Porém, para ambas as salas, reduções significativas nas cargas máximas foram obtidas comparando-se os dois cenários de ar-condicionado. Nesse sentido, o aumento da temperatura de $24^{\circ} \mathrm{C}$ para $26^{\circ} \mathrm{C}$ durante o mês mais quente mostrou uma redução equivalente a $20 \%$ na carga térmica e, considerando-se o restante do ano, este valor sobre para $35 \%$.

\begin{tabular}{l|l|l|l|l|l|l}
\hline & \multicolumn{3}{|c|}{$\begin{array}{l}\text { Carga total anual (KW) } \\
\text { (ar condicionado - a/c) }\end{array}$} & \multicolumn{3}{c}{ Carga máxima (W) } \\
\hline \multirow{3}{*}{$\begin{array}{l}\text { Gabinete/ } \\
\text { Sala }\end{array}$} & $\begin{array}{l}\text { a/c integral } \\
\text { vidro } \\
\text { laminado 6 } \\
\mathrm{mm}\end{array}$ & $\begin{array}{l}\text { modo-misto } \\
\text { vidro } \\
\text { laminado 6 } \\
\mathrm{mm}\end{array}$ & $\begin{array}{l}\text { modo-misto } \\
\text { vidro laminado } \\
\text { com camada } \\
\text { de ar } \\
10+28+6 \mathrm{~mm}\end{array}$ & $\begin{array}{l}\text { a/c integral } \\
\text { vidro } \\
\text { laminado 6 } \\
\mathrm{mm}\end{array}$ & $\begin{array}{l}\text { modo- } \\
\text { misto vidro } \\
\text { laminado 6 } \\
\mathrm{mm}\end{array}$ & $\begin{array}{l}\text { modo-misto } \\
\text { vidro laminado } \\
\text { com camada de } \\
\text { ar 10+28+6mm }\end{array}$ \\
\hline Norte & 2,7 & 2,4 & 2,4 & 2.281 & 1.604 & 1.620 \\
\hline Sul & 1,2 & 1,1 & 1,1 & 1.383 & 772 & 722 \\
\hline
\end{tabular}

Tabela 3 - Carga térmica total anual e carga térmica máxima dos gabinetes de escritórios nos laboratórios: ar condicionado $26^{\circ} \mathrm{C}-65 \%$ UR

\begin{tabular}{l|c|c|c|c|c|c}
\hline \multirow{2}{*}{$\begin{array}{l}\text { Gabinete/ } \\
\text { Sala }\end{array}$} & \multicolumn{3}{|c|}{ Carga máxima (kW) } & \multicolumn{2}{c}{ Carga total (MW) } \\
\cline { 2 - 7 } & $22^{\circ} \mathrm{C} / 50 \%$ & $24^{\circ} \mathrm{C} / 50 \%$ & $24^{\circ} \mathrm{C} / 50 \%$ & $26^{\circ} \mathrm{C} / 65 \%$ & $24^{\circ} \mathrm{C} / 50 \%$ & $26^{\circ} \mathrm{C} / 65 \%$ \\
\hline Norte & 1,48 & 1,21 & 1,82 & 1,12 & 2,2 & 1,1 \\
\hline Sul & 1,57 & 1,29 & 1,87 & 1,26 & 2,2 & 1,2 \\
\hline
\end{tabular}

Tabela 4 - Carga térmica total anual e carga térmica máxima dos gabinetes de escritórios nos laboratórios: avaliação do modo-misto 


\begin{tabular}{l|c|c|c}
\hline \multirow{2}{*}{$\begin{array}{l}\text { Gabinete/ } \\
\text { Sala }\end{array}$} & \multicolumn{2}{|c|}{ Carga máxima $(\mathbf{k W})$} & Carga total (MWh) \\
\cline { 2 - 4 } & Fevereiro & Anual & Anual \\
\cline { 2 - 4 } & $22^{\circ} \mathrm{C} / 50 \%$ & $24^{\circ} \mathrm{C} / 50 \%$ & $24^{\circ} \mathrm{C} / 50 \%$ \\
\hline Norte & 2,29 & 1,76 & 2,3 \\
\hline Sul & 2,45 & 1,91 & 2,3 \\
\hline
\end{tabular}

Tabela 5 - Carga térmica total anual e carga térmica máxima dos gabinetes de escritórios nos laboratórios: simulações finais

\begin{tabular}{c|c|c|c}
\hline Ala/ pavimento & Frio (\%) & Calor (\%) & Conforto (\%) \\
\hline Ala oeste ( $\mathbf{1}^{\circ}$ pavimento) & 2,2 & 59,3 & 38,5 \\
\hline Ala leste $\left(2^{\circ}\right.$ pavimento) & 1,3 & 62,2 & 36,5 \\
\hline
\end{tabular}

Tabela 6 - Escritórios do Prédio Central: porcentagem das horas de ocupação do ano em conforto

A análise das cargas térmicas totais anuais evidenciou uma redução de $42 \%$ com a alteração dos parâmetros de temperatura (cargas sensíveis), enquanto que o aumento de UR de $50 \%$ para $65 \%$ (cargas latentes) proporcionou cargas totais anuais $42 \%$ menores. Paralelamente, o período potencial de ventilação natural com o modo-misto, considerando-se as horas ocupadas, foi identificado entre maio e setembro, mantendo-se os parâmetros do ar-condicionado a $24^{\circ} \mathrm{C}$ e $50 \%$ UR. A operação do sistema a $26^{\circ} \mathrm{C}$ e $65 \%$ UR provou expandir o período de ventilação natural em um mês, equivalente a uma redução de $10 \%$ nas horas de ar-condicionado.

As janelas foram consideradas totalmente abertas para ventilação noturna das $17 \mathrm{~h}$ às $7 \mathrm{~h}$ e, portanto, entende-se que o real período de ventilação natural deverá ser maior do que o indicado nas simulações.

Em função disso, considerando-se $24^{\circ} \mathrm{C}$ e $50 \%$ UR a porcentagem anual de ventilação natural durante as horas ocupadas do gabinete norte é de 12,2\%, sendo similar ao gabinete sul, com 13,3\%. Alterando-se os parâmetros de operação para $26^{\circ} \mathrm{C}$ e $65 \%$ UR, a porcentagem anual de ventilação natural aumenta para $21,2 \%$, a norte, e $23,1 \%$, a sul.

\section{Simulações finais}

As paredes externas dos gabinetes foram substituídas, mais uma vez, por painéis de concreto pré-moldado de $12 \mathrm{~cm}$ de espessura, com revestimento. As paredes internas, por sua vez, foram especificadas com sistema dry wall. Essa alteração não foi formulada com base nos resultados prévios das análises de desempenho, mas sim, em questões construtivas estabelecidas pelo projeto de arquitetura.

Outra mudança foi a redução do vão efetivo das aberturas para a ventilação natural para $50 \%$, ao invés dos anteriores $80 \%$, baseado no projeto das esquadrias. No período de climatização artificial, a avaliação final considerou as condições de $24^{\circ} \mathrm{C}$ e $50 \%$ UR. Os parâmetros do termostato foram avaliados, também, para as cargas máximas durante o mês mais quente, incluindo um segundo cenário de $22^{\circ} \mathrm{C}$ e $50 \%$ UR, segundo o projeto dos sistemas prediais.

Como resultado, encontrou-se um aumento nas cargas térmicas durante os períodos de arcondicionado nos gabinetes, em comparação à configuração anterior. As cargas máximas foram mais elevadas no gabinete sul, como conseqüência da radiação solar incidente, evidenciando a necessidade de proteção solar. É possível observar na Tabela 6 que as cargas máximas no mês mais quente foram significativamente mais altas em ambos os casos, em até $50 \%$, quando comparadas aos resultados anteriores. Paralelamente, as cargas totais anuais aumentaram 5\%, o equivalente a 1 MWh para cada gabinete.

Considerando-se os períodos de ventilação natural e o modo-misto, as mudanças nos materiais trouxeram um aumento de aproximadamente $15 \%$ no período potencial de ventilação natural, entre maio e outubro, em ambos os gabinetes, com o arcondicionado a $24^{\circ} \mathrm{C}$ e $50 \%$ UR. Ressalta-se o efeito compensatório de tal aumento em relação à elevação nas cargas térmicas para os períodos de ar-condicionado, conforme Tabela 5.

\section{Escritórios do Prédio Central}

O Prédio Central tem $245 \mathrm{~m}$ de comprimento e três pavimentos, orientado a leste e oeste, elevado sobre pilotis, sendo o primeiro andar de piso técnico e os outros dois de escritórios, compostos por duas alas paralelas conectadas por um corredor de circulação interna aberta, para o qual são voltadas áreas envidraçadas nos fechamentos verticais.

Enquanto a ala leste é formada por um bloco de dois pavimentos, a ala oeste possui apenas um, com terraços na cobertura de cada bloco. Uma grande cobertura protege todo o edifício, 
sombreando os terraços e os escritórios. Esse edifício atravessa o complexo na direção norte-sul, conectando o Centro de Convenções, os Laboratórios e o grande Restaurante no nível térreo (Figura 10).

A cobertura que protege todo o edifício é um dos aspectos fundamentais do partido arquitetônico e da concepção ambiental, na medida em que cria condições de ocupação nos terraços e sombreia a laje dos escritórios (Tabela 7). Inicialmente, a cobertura era constituída por chapas metálicas perfuradas, permeáveis à radiação solar e à ventilação.

\section{$1^{\circ}$ cenário simulado: análise do potencial de ventilação natural}

As simulações foram realizadas para dois escritórios, localizados em diferentes pavimentos e orientações, com $665 \mathrm{~m}^{2}$ de área útil cada e pé- direito de 2,80 m. Na primeira etapa, esses ambientes eram caracterizados por materiais leves e isolantes, com acabamento externo metálico branco e janelas de vidro laminado incolor $6 \mathrm{~mm}$.

$\mathrm{Na}$ primeira simulação foi considerado um vão efetivo para a ventilação de $50 \%$ das aberturas, durante as horas de trabalho, e $100 \%$ durante as horas não ocupadas, das $17 \mathrm{~h}$ às $7 \mathrm{~h}$. Nos finais de semana e feriados, as janelas foram consideradas totalmente abertas (Figura 11).

Nessa primeira etapa a cobertura original foi comparada com uma solução composta por painéis-sanduíche metálicos e duas faixas longitudinais com vidro laminado incolor $6 \mathrm{~mm}$, sobre a circulação central, para proteger os terraços de chuva e, ainda, permitir a penetração controlada da radiação solar.

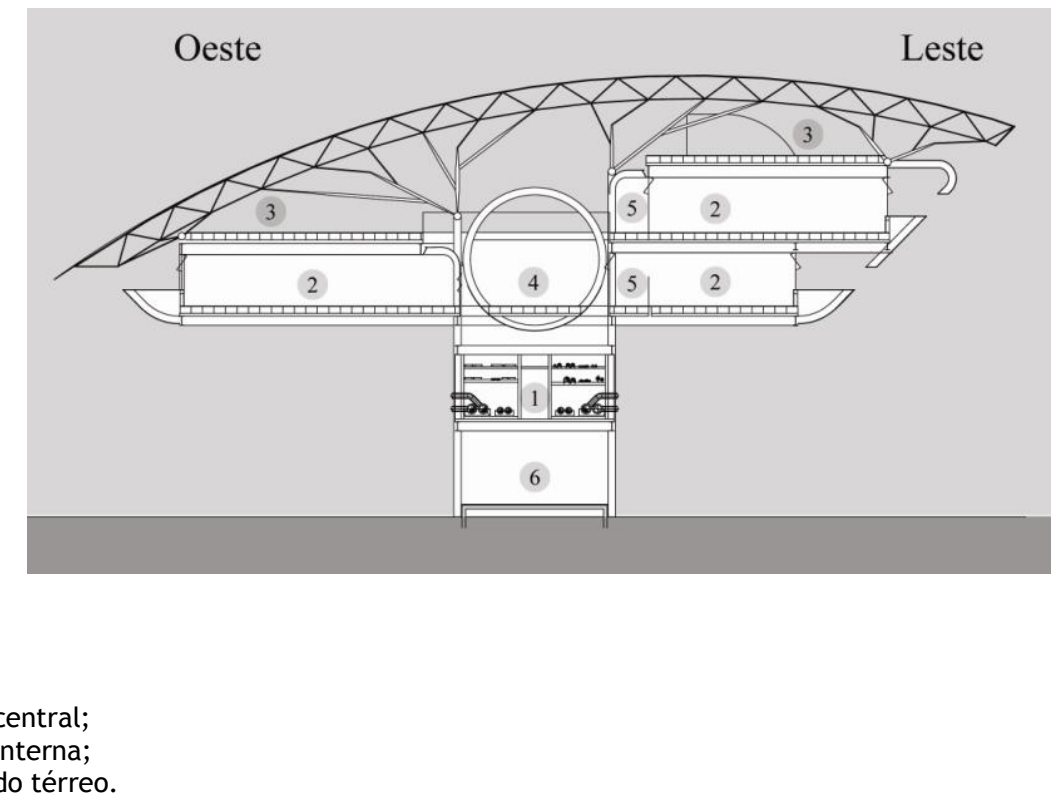

Legenda:

1 Pipe-rack;

2 Escritórios:

3 Terraços:

4 Circulação central;

5 Circulação interna;

6 Circulação do térreo.

Figura 10 - Prédio Central: seção transversal mostrando a composição dos espaços internos

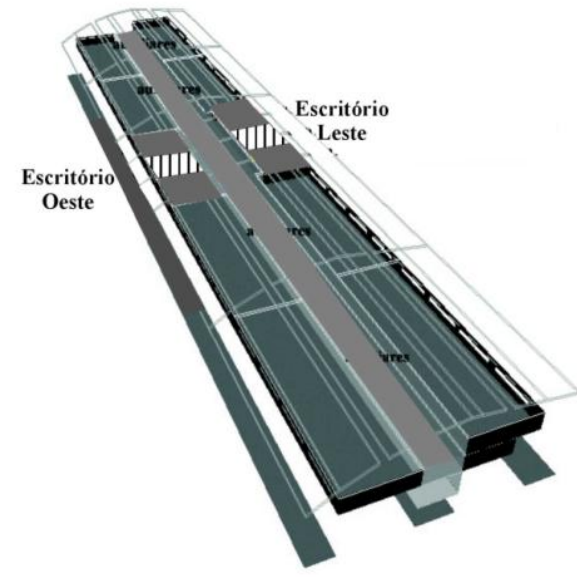

20 Marcondes, M. P.; Mueller, C. M.; Brandão, R. S. B.; Shimomura, A. R. P.; Brunelli, G.; Paes Leme, G. S. De B.; Gonçalves, J. C. S.; Duarte, D. H. S.; Frota, A. B. 
Figura 11 - Modelo esquemático dos ambientes de trabalho do Edifício Central, incluindo os ambientes selecionados para a avaliação de desempenho térmico

As simulações de ventilação natural nos escritórios, com PPD de $20 \%$, resultaram em $38,5 \%$ das horas em conforto no ano no escritório do $1^{\circ}$ pavimento, a oeste, e $36,5 \%$ no escritório do $2^{\circ}$ pavimento, a leste - o que enfatiza a importância de aberturas operáveis (Tabela 6). Outro resultado relevante foi a melhoria do desempenho térmico considerando-se a grande cobertura de painéis sanduíche, $20 \%$ maior do que os resultados obtidos com a solução de chapas metálicas perfuradas.

Mesmo assim, os resultados positivos no conforto térmico dos escritórios devem ser avaliados face ao impacto dessa solução na diversidade das condições ambientais dos terraços. A cobertura também foi avaliada conforme critérios de conforto em espaços externos e desempenho luminoso.

Nessas simulações, as janelas foram consideradas abertas durante todo o tempo e, por esse motivo, as horas de frio poderiam se tornar horas de conforto simplesmente com o controle da ventilação, resultando em um potencial para ventilação natural por $40 \%$ do ano. Por fim, ocorreu um ganho significativo de cargas térmicas através da superfície de vidro das fachadas internas das alas de escritórios que estão voltadas para a circulação central descoberta.

\section{$2^{\circ}$ cenário de simulação: análise do modo- misto versus ar condicionado por período integral}

Partindo das análises de ventilação natural nos ambientes de trabalho, foi testado o potencial do modo-misto.

Seguindo os mesmos parâmetros utilizados nas simulações dos gabinetes dos Laboratórios, testouse o vidro laminado incolor com camada de ar $10+28+6 \mathrm{~mm}$ contra o vidro laminado incolor 6 mm. Devido a questões acústicas as janelas localizadas na fachada oeste da ala oeste do edifício foram consideradas fixas e, sendo assim, a incorporação de ventilação natural nesses escritórios seria possível apenas por meio das janelas voltadas para a circulação central, o que limita bastante os seus efeitos.

Conforme o projeto arquitetônico foi sendo desenvolvido, alterações na cobertura foram propostas e testadas (Tabela 8). Uma composição das duas opções anteriores, formada por uma área central de telha-sanduíche e faixas laterais de telhas metálicas perfuradas foi avaliada, com base no seu desempenho térmico e luminoso. O beiral da cobertura a oeste manteve-se parcialmente permeável à radiação solar e, desse modo, à luz natural, como um brise soleil linear contínuo, composto por aletas.

A solução da cobertura teve um impacto positivo no corte dos ganhos solares dos escritórios. Já a opção por janelas com vidro laminado com camada de ar 10+28+6 mm não mostrou benefícios significativos para o conforto térmico.

Com relação à eficiência energética, o modo-misto comprovadamente contribuiu para a redução das cargas térmicas dos escritórios, conforme Tabela 8. Por outro lado, as cargas totais anuais sofreram um acréscimo de $1 \%$ no escritório leste e 5\% no escritório oeste (que possui janelas externas fixas e, conseqüentemente, menores taxas de ventilação). Nesse caso, os resultados para o escritório oeste sofreram maior influência da radiação solar, devido à permeabilidade dos dispositivos de proteção.

Concluindo, pode-se dizer que o projeto arquitetônico e os parâmetros de operação exerceram impacto significativo no modo-misto, tais como a redução da área envidraçada voltada para a circulação central, onde foram identificados os ganhos solares mais relevantes. Enquanto a ala leste mostrou potencial para o modo-misto, a ala oeste mostrou o oposto, para a qual o arcondicionado durante todo o tempo de ocupação é a solução mais adequada. Particularmente nesse caso, as janelas de vidro laminado com camada de ar $10+28+6 \mathrm{~mm}$ foram recomendadas para ambas as fachadas da ala oeste, com a finalidade de aumentar a eficiência energética do sistema de arcondicionado.

\section{$3^{\circ}$ cenário de simulação: análise do modo- misto versus ar condicionado, fase II}

Partindo dos resultados anteriores, o escritório oeste foi considerado com ar-condicionado por todo o tempo de ocupação. Para esse caso, o uso de vidro laminado com camada de ar $10+28+6 \mathrm{~mm}$ foi novamente testado. Para os escritórios a leste, por sua vez, a estratégia de modo-misto continuou a ser investigada.

A aplicação de vidro laminado verde $7 \mathrm{~mm}$ nas fachadas internas de ambos os escritórios, leste e oeste, voltadas para a circulação aberta interna, e vidro laminado incolor $7 \mathrm{~mm}$ nas fachadas externas, foi testada e comparada à aplicação de vidro laminado incolor $7 \mathrm{~mm}$ em todas as janelas. 
Também nessa etapa foram testadas paredes externas mais leves, com revestimento externo em alumínio e isolante termoacústico na face interna, forros absorvedores acústicos e divisórias internas de piso a forro. Também foi incluída uma abertura linear na cobertura, ao longo do comprimento do edifício, para a saída do ar, a fim de evitar o acúmulo de calor.
Considerando-se a ala leste operando em modomisto, o uso do vidro laminado verde nas janelas da fachada voltada para a circulação central, com o ar-condicionado operando a $26^{\circ} \mathrm{C}$ e $65 \%$ UR, resultou em uma redução de $3,8 \%$ nas cargas de resfriamento anuais totais, em oposição ao uso do vidro laminado incolor em ambas as fachadas desse bloco, conforme Tabela 10.

\section{Solução original \\ chapa metálica perfurada}
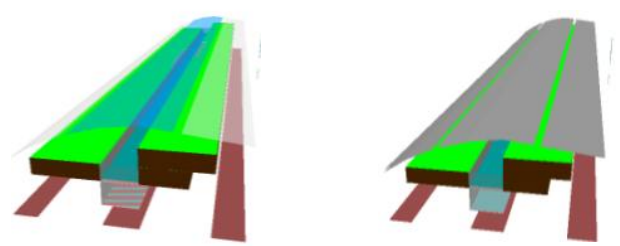

$2^{\circ}$ etapa de simulações

chapa metálica perfurada (40\% vazios)+ painel sanduíche e vidro verde laminado $6 \mathrm{~mm}$ no centro

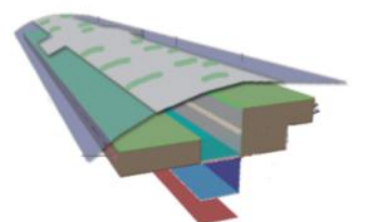

$3^{\circ}$ etapa de simulações e simulações finais chapa metálica perfurada (40\% vazios)+ painel sanduíche e vidro verde laminado $7 \mathrm{~mm}+1$ shed central (30\% abertura)

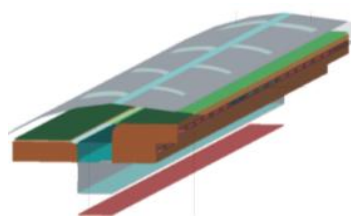

Tabela 7 - Soluções de cobertura testadas nas simulações dos escritórios do Edifício Central

\begin{tabular}{l|l|l|l|l}
\hline & \multicolumn{2}{|l|}{ Carga anual total (MW) } & \multicolumn{2}{l}{ Carga máxima (W) } \\
\hline \multirow{2}{*}{$\begin{array}{l}\text { Escritório/ } \\
\text { Sala }\end{array}$} & a/c integral & modo-misto & a/c integral & modo-misto \\
& vidro laminado & vidro laminado & vidro laminado & vidro laminado \\
& $6 \mathrm{~mm}$ & $6 \mathrm{~mm}$ & $6 \mathrm{~mm}$ & $6 \mathrm{~mm}$ \\
\hline Leste & 37,9 & 39,4 & 33.738 & 32.010 \\
\hline Oeste & 40,3 & 42,1 & 34.703 & 33.962 \\
\hline
\end{tabular}

Tabela 8 - Carga térmica anual e carga térmica máxima de resfriamento para salas de escritórios leste e oeste do Prédio Central: $a / c 26^{\circ} \mathrm{C}$ e $65 \%$ UR

\begin{tabular}{l|c|c|c}
\hline \multirow{4}{*}{ escritório/ sala } & \multicolumn{3}{|c}{ carga total anual (MWh) } \\
\cline { 2 - 4 } & $\begin{array}{c}\text { vidro laminado } \\
\text { incolor 7 mm }\end{array}$ & \multicolumn{2}{c}{$\begin{array}{c}\text { vidro laminado incolor } \\
\text { 7 mm e vidro laminado } \\
\text { verde 7 mm }\end{array}$} \\
\cline { 2 - 4 } & $26^{\circ} \mathrm{C} / 65 \%$ & $26^{\circ} \mathrm{C} / 65 \%$ & $24^{\circ} \mathrm{C} / 50 \%$ \\
\hline Leste (modo-misto) & 58,8 & 57,0 & 79,1 \\
\hline Oeste (a/c integral) & 62,9 & 61,8 & 81,3 \\
\hline
\end{tabular}

Tabela 9 - Cargas totais anuais para as salas de escritórios leste e oeste do Prédio Central, com diferentes vidros e configurações de ar condicionado

\begin{tabular}{l|c}
\hline \multicolumn{1}{c|}{ Edifício } & Conforto (\%) \\
\hline 1 Centro de Convenções & \\
\hline Restaurante/ Lanchonete & 69,2 \\
\hline Área de Eventos & 59,8 \\
\hline 2 Empreiterópolis & \\
\hline Refeitório & 65,8 \\
\hline Cozinha quente & 52,0 \\
\hline Vestiários & 75,0 \\
\hline 3 Oficinas & \\
\hline Oficina & 54,6 \\
\hline 4 Planta-Piloto & \\
\hline Abastecimento & 57,0 \\
\hline
\end{tabular}

Tabela 10 - Frequiência de horas em conforto nos edifícios de tipologia galpão naturalmente ventilados, considerando-se PPD de $20 \%$ 

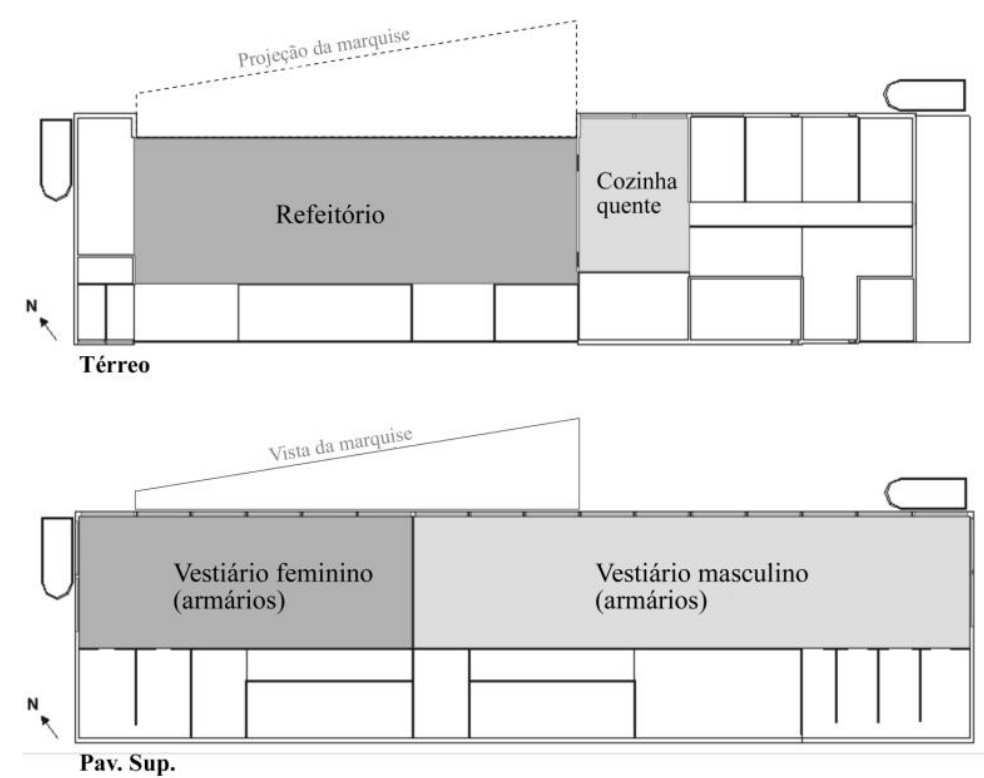

Figura 12 - Ambientes da Empreiteirópolis selecionados para a avaliação de desempenho térmico

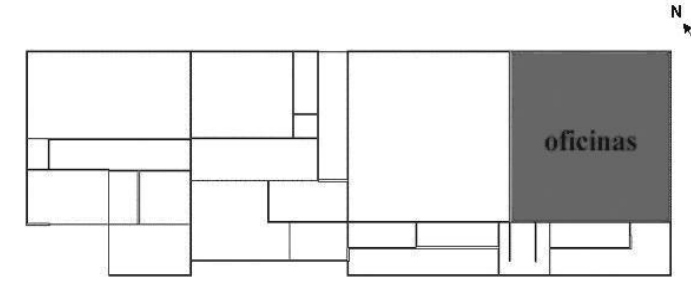

térreo

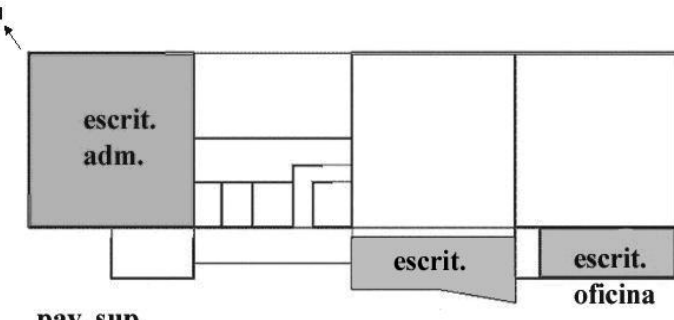

pav. sup.

Figura 13 - Ambientes das Oficinas selecionados para a avaliação de desempenho térmico

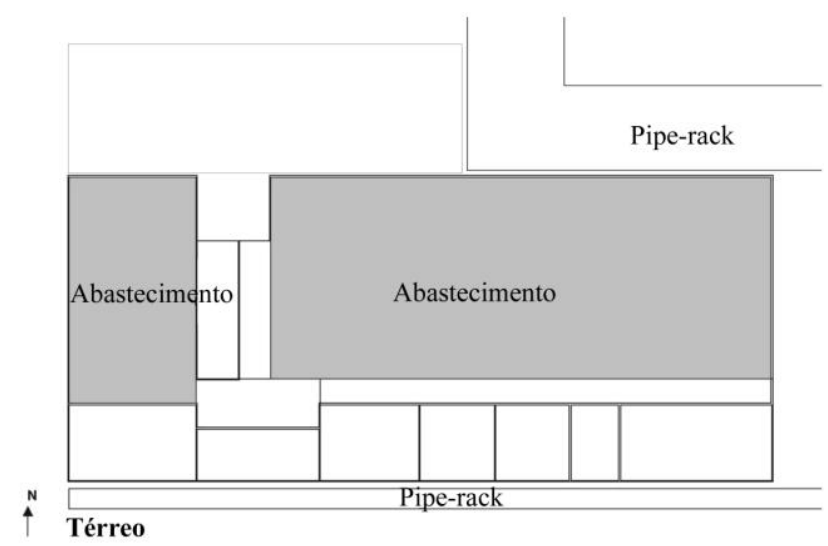

Figura 14 - Ambientes da Planta-Piloto selecionados para a avaliação de desempenho térmico

\section{Avaliação de desempenho térmico de galpões \\ naturalmente ventilados}

\section{As intervenções no projeto}

Dos quatro galpões do complexo, com coberturas em shed, três contaram com a ventilação natural, combinando efeito de vento e efeito chaminé:
Empreiteirópolis, Oficinas e Planta-Piloto (Figuras 12,13 e 14).

A princípio, a orientação original das aberturas na cobertura (voltada para a direção predominante dos ventos) foi o principal fator de influência no desempenho desfavorável da ventilação natural dos espaços internos. Por essa razão, os sheds foram redesenhados, reposicionando as suas aberturas para a parte superior do plano vertical, incluindo um elemento de proteção solar e 
proteção contra o vento predominante, conforme Figura 15. Dessa forma, sem alterar a orientação dos mesmos, foi possível evitar os efeitos desfavoráveis dos ventos predominantes na saída de ar e, ao mesmo tempo, tirou-se proveito da pressão negativa para maximizar a exaustão do mesmo.

Mesmo assim, os resultados das primeiras simulações para os vestiários da Empreiteirópolis e para as Oficinas mostraram que a ventilação natural ainda era insuficiente.

Simulações de dinâmica de fluidos foram realizadas para os três edifícios, conforme Figura 16, que ilustra o caso da Empreiteirópolis. A partir daí foram extraídos os coeficiente de pressão para o cálculo do desempenho térmico, além de uma visualização da distribuição da ventilação no ambiente.

Nos vestiários da Empreiterópolis, a ausência de tomadas inferiores de ar também restringiu a ventilação, resultando em condensação superficial nas paredes e cobertura. Aberturas altas foram adicionadas nas fachadas a sotavento, aumentando assim a área de exaustão, estratégia esta também adotada nas Oficinas, onde os ganhos de calor por equipamentos são elevados e apenas o shed servia como saída para a ventilação natural.

A ventilação forçada nos vestiários da Empreiterópolis também foi considerada para melhorar as condições de conforto, com insuflamento e exaustão de ar nas áreas de chuveiros (15 trocas/h) e armários (10 trocas $/ \mathrm{h})$. A cozinha, no térreo, também teve uma taxa de exaustão simulada em 30 trocas/h. Foi proposta então uma ventilação mecânica com essa taxa, sendo que a exaustão deve ser pontual em cada equipamento para minimizar o aquecimento do ambiente, pois a perda pela ventilação natural não é suficiente, mesmo com a abertura de $50 \%$ das janelas altas basculantes.
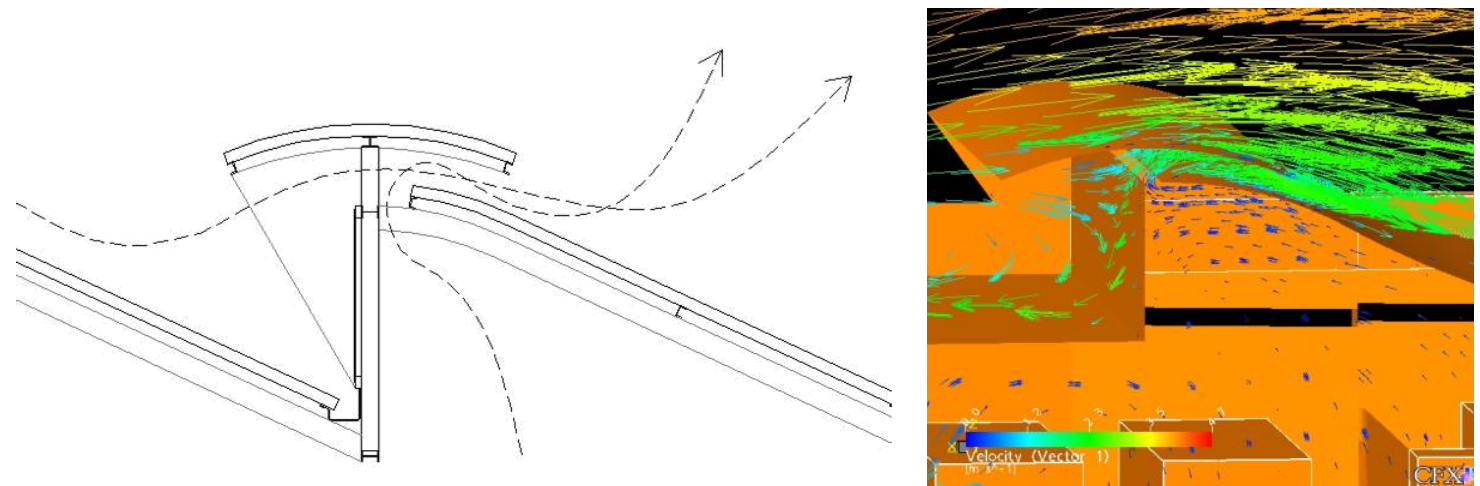

Figura 15 - Detalhe e simulação da saída de ar do shed com proteção para a saída do vento, comum aos edifícios do complexo que seguem a tipologia do edifício industrial

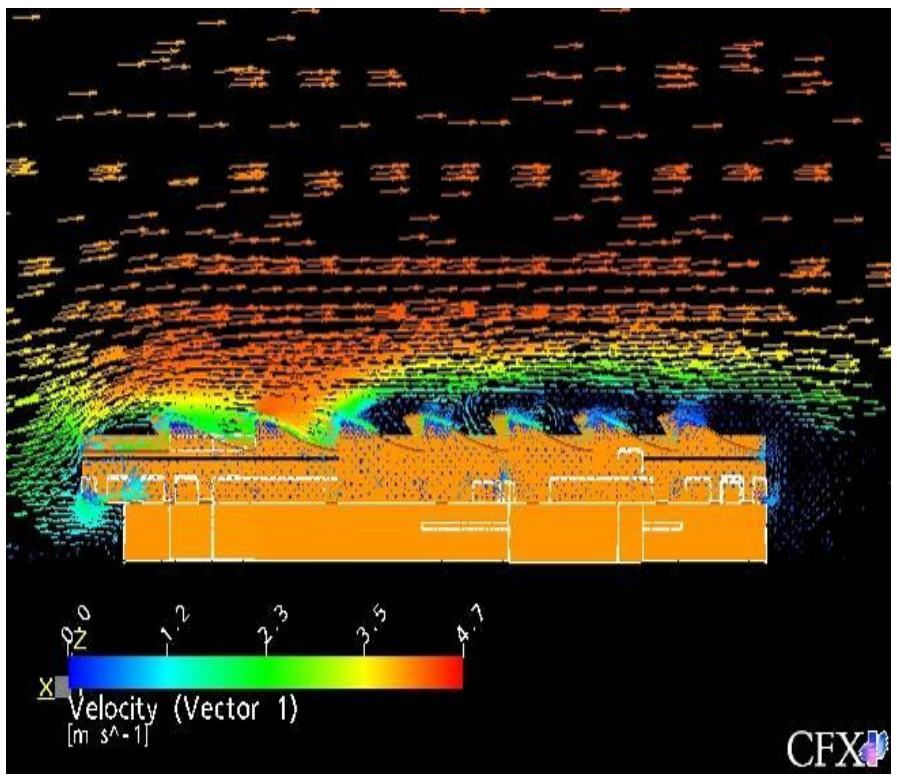

Figura 16 - Estudos de simulação da ventilação nos galpões

24 Marcondes, M. P.; Mueller, C. M.; Brandão, R. S. B.; Shimomura, A. R. P.; Brunelli, G.; Paes Leme, G. S. De B.; Gonçalves, J. C. S.; Duarte, D. H. S.; Frota, A. B. 


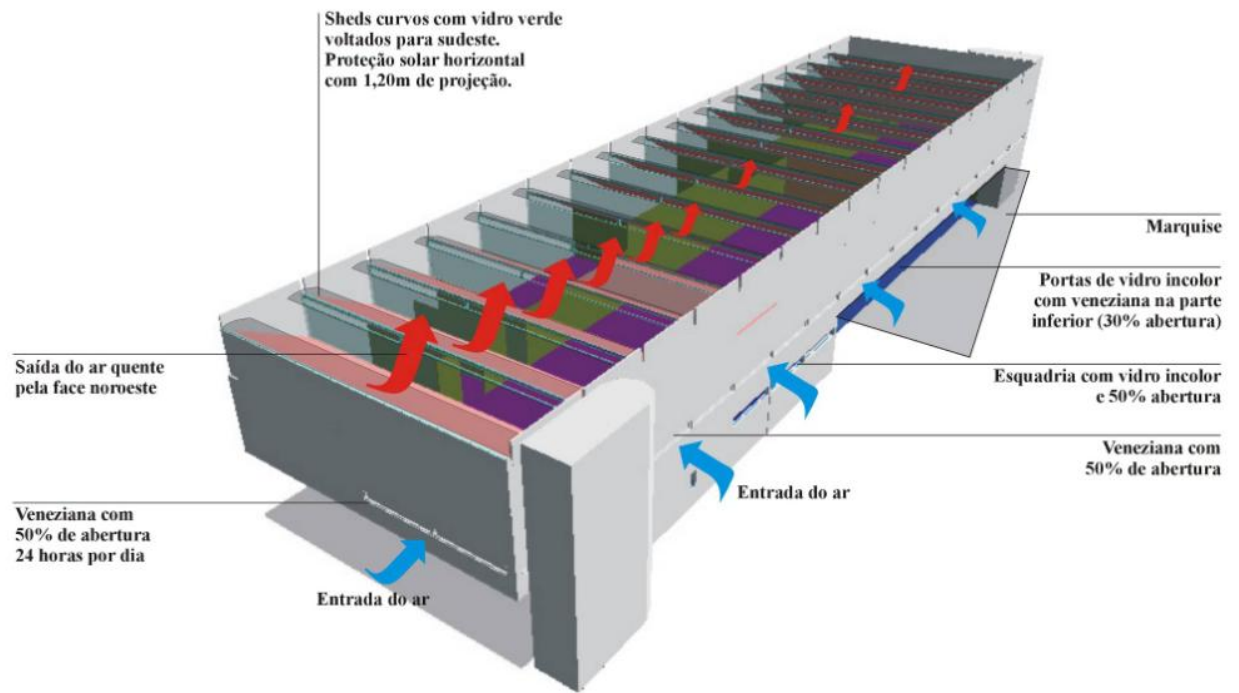

Figura 17 - Modelo esquemático da Empreiteirópolis e as estratégias para o desempenho ambiental

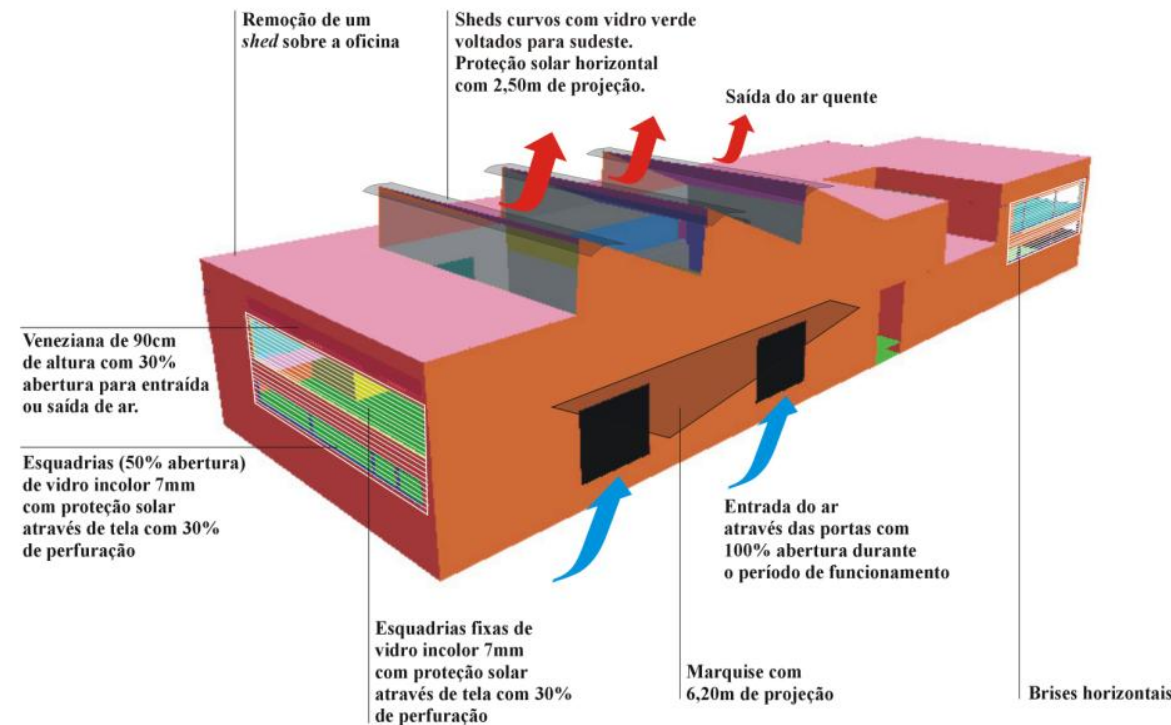

Figura 18 - Modelo esquemático das Oficinas e estratégias para o desempenho ambiental

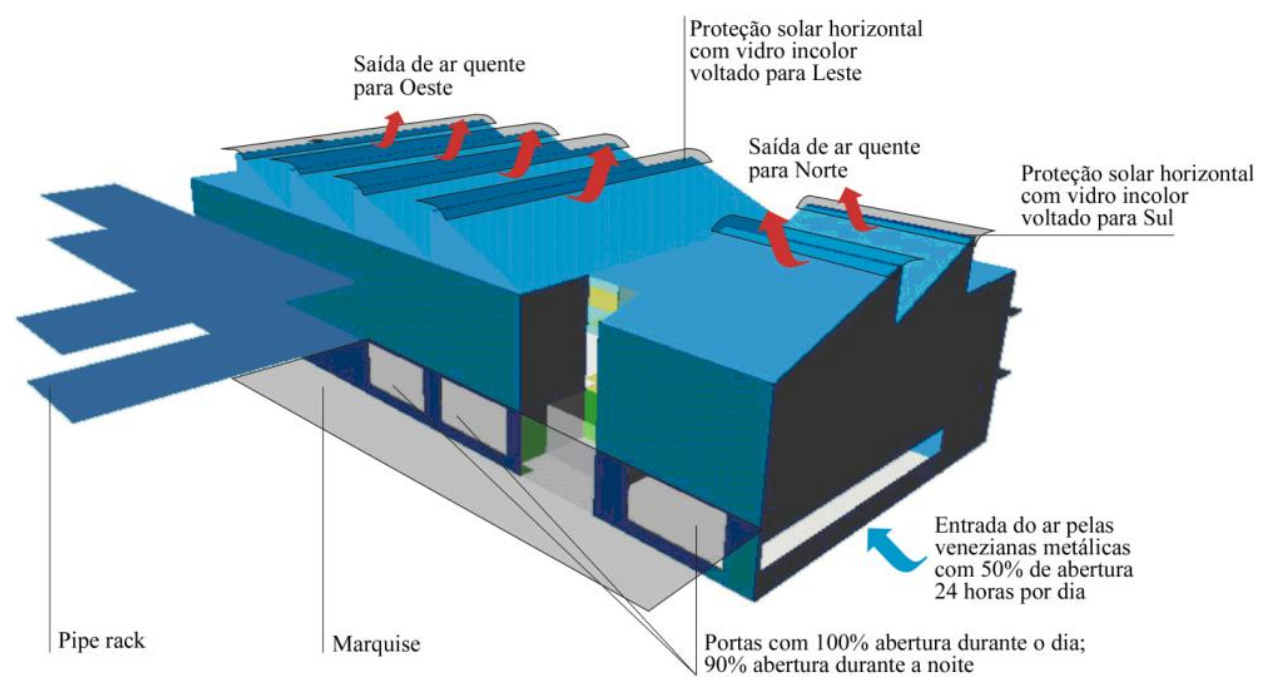

Figura 19 - Modelo esquemático da Planta-Piloto e as estratégias para o desempenho ambiental 
Alterações também foram propostas para os materiais como, por exemplo, maior isolamento térmico entre a cozinha e o refeitório. Além disso, proteções solares externas foram propostas para as janelas e para as aberturas na cobertura de todos os galpões (Figuras 17, 18 e 19).

\section{Resultados das análises de conforto térmico}

Os ambientes analisados mostraram um desempenho satisfatório após as alterações propostas, com PPD de 20\% (Tabela 10).

A cozinha e o refeitório da Empreiteirópolis mostraram-se dentro da zona de conforto durante $52 \%$ e $65,8 \%$ do período de ocupação anual, respectivamente. A cozinha contou com uma ventilação mecânica de 30 trocas/h, além de alterações nos materiais e incremento de aberturas para ventilação natural, para se chegar a esse resultado. Sem essas melhorias a porcentagem das horas do ano em conforto não passava de 8,5\%.

Os vestiários, onde a carga térmica foi reduzida em $40 \%$ devido às alterações propostas (proteção solar mais eficiente das áreas envidraçadas dos sheds, incremento da ventilação por efeito chaminé com a colocação de venezianas altas na fachada sudoeste e divisórias baixas nos vestiários) e onde foi acrescida a ventilação mecânica de 10 trocas $/ \mathrm{h}$, apresentaram níveis de conforto por mais de $75 \%$ do período de ocupação, que anteriormente não chegavam a $10 \%$.

Já nas Oficinas e Planta-Piloto, os espaços ventilados naturalmente mostraram-se em conforto durante respectivamente $54,6 \%$ e $57 \%$ das horas ocupadas ao longo do ano. $\mathrm{O}$ valor apresentado na Tabela 10 para a Planta-Piloto não considerou a inclusão de ventilação mecânica de 20 trocas/h testada em simulação, pois não representou uma melhora significativa na média anual (ficando em torno de $2 \%$ ). Isso indica que a ventilação natural do ambiente já está otimizada.

\section{Avaliação de desempenho térmico do centro de convenções}

Esse edifício tem planta circular e organiza-se em torno de um jardim central. É composto por salas multiuso independentes, um salão de eventos e um hall de acesso, todo ele coberto por uma membrana têxtil tensionada que protege o espaço da chuva e da radiação solar direta e que definiu o aproveitamento de iluminação natural nas salas.
Destacando-se da membrana, no ponto mais alto, tem-se um grande auditório e um foyer, ambos selados. Sob o auditório há uma praça de alimentação não confinada, voltada para o jardim (Figura 20).

O edifício tem alguns espaços com alta densidade de ocupação e necessidade de controle das condições ambientais. Por isso, determinou-se que esses locais fossem permanentemente condicionados artificialmente. Os requisitos de isolamento acústico foram decisivos nas etapas iniciais do projeto e determinaram a escolha dos materiais, resultando também em componentes com alto isolamento térmico. A adoção da membrana reduziu significativamente a radiação na cobertura e em algumas das paredes das salas, diminuindo os ganhos de calor pela envoltória.

Para a Área de Eventos considerou-se uma ocupação das $9 \mathrm{~h}$ às $21 \mathrm{~h}$ com carga térmica de $41 \mathrm{~W} / \mathrm{m}^{2}$, sendo que a carga de ocupação foi retirada durante o horário do almoço (13h) e jantar (18h). Para o restaurante e a lanchonete, a ocupação era das $8 \mathrm{~h}$ às $21 \mathrm{~h}$ com carga térmica de $7,1 \mathrm{~W} / \mathrm{m}^{2}$ na área de consumo e $20 \mathrm{~W} / \mathrm{m}^{2}$ na cozinha.

Os ganhos de calor pela iluminação artificial foram considerados de $12 \mathrm{~W} / \mathrm{m}^{2}$ após as $18 \mathrm{~h}$ apenas. $\mathrm{Na}$ área de eventos não havia iluminação artificial durante o dia e, no restaurante, a carga era de 2 $\mathrm{W} / \mathrm{m}^{2}$ entre $11 \mathrm{~h}$ e $17 \mathrm{~h}$. Como carga de equipamentos, foram considerados $8 \mathrm{~W} / \mathrm{m}^{2}$ para a área de restaurante durante as horas ocupadas. Os acessos ficam abertos para o exterior durante 24 horas.

Nas simulações iniciais, verificou-se condições de conforto por até $37,4 \%$ das horas ocupadas no restaurante, mas alterações nos materiais e no projeto interferiram na ventilação e aumentaram o ganho de calor, reduzindo esse valor para $12 \%$ na segunda simulação. O salão de eventos apresentou somente $15 \%$ das horas em conforto, principalmente devido à alta temperatura radiante causada pela transmissão solar na cobertura.

A partir daí, novas alterações foram propostas. As principais foram a duplicação da membrana sobre o hall de eventos e as alterações nas aberturas de ventilação para melhorar o fluxo de vento, apresentadas em conjunto com as demais estratégias na Figura 21.

A simulação termodinâmica foi informada por simulações de dinâmica dos fluidos para a determinação dos coeficientes de troca das áreas ventiladas, para a necessidade de aberturas e para os valores médios de velocidade de vento nas áreas ocupadas (Figura 22). 

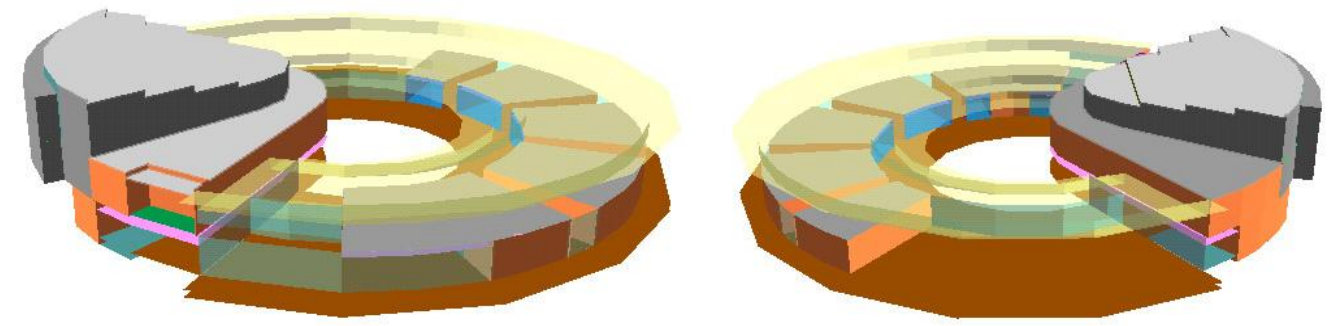

Figura 20 - Modelo de simulação térmica do Centro de Convenções

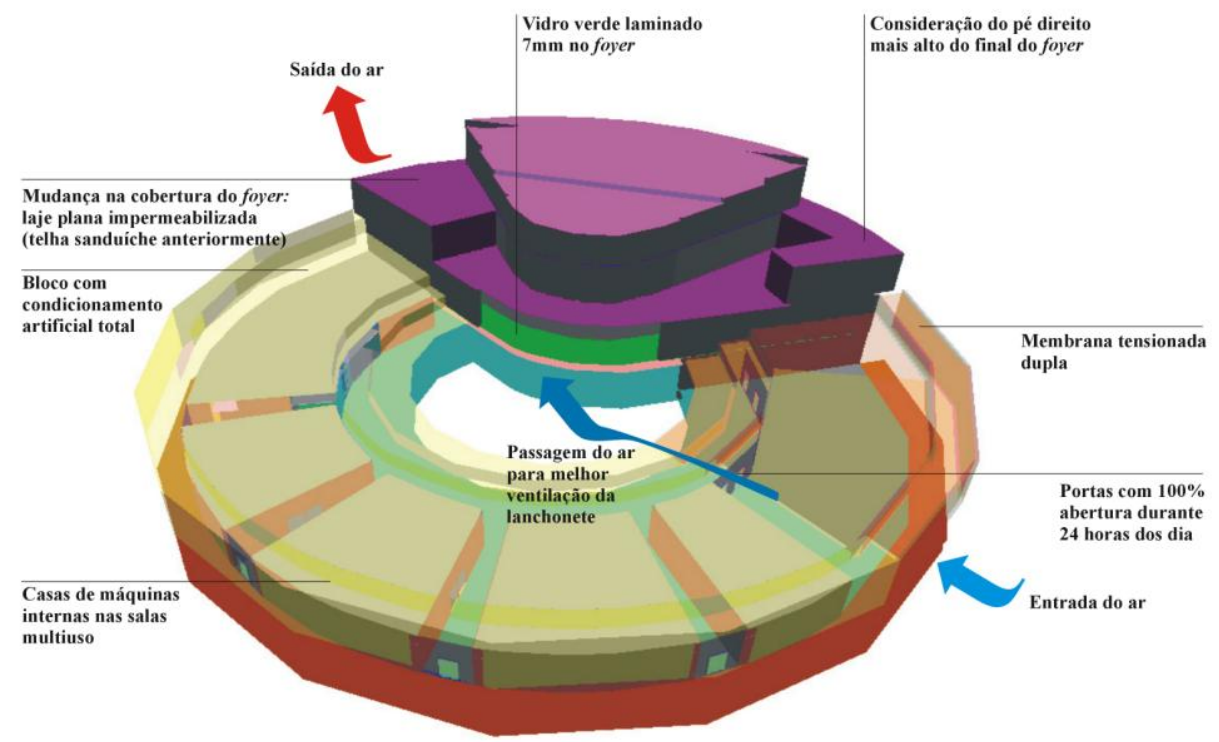

Figura 21 - Modelo esquemático do Centro de Convenções com as estratégias para o desempenho ambiental
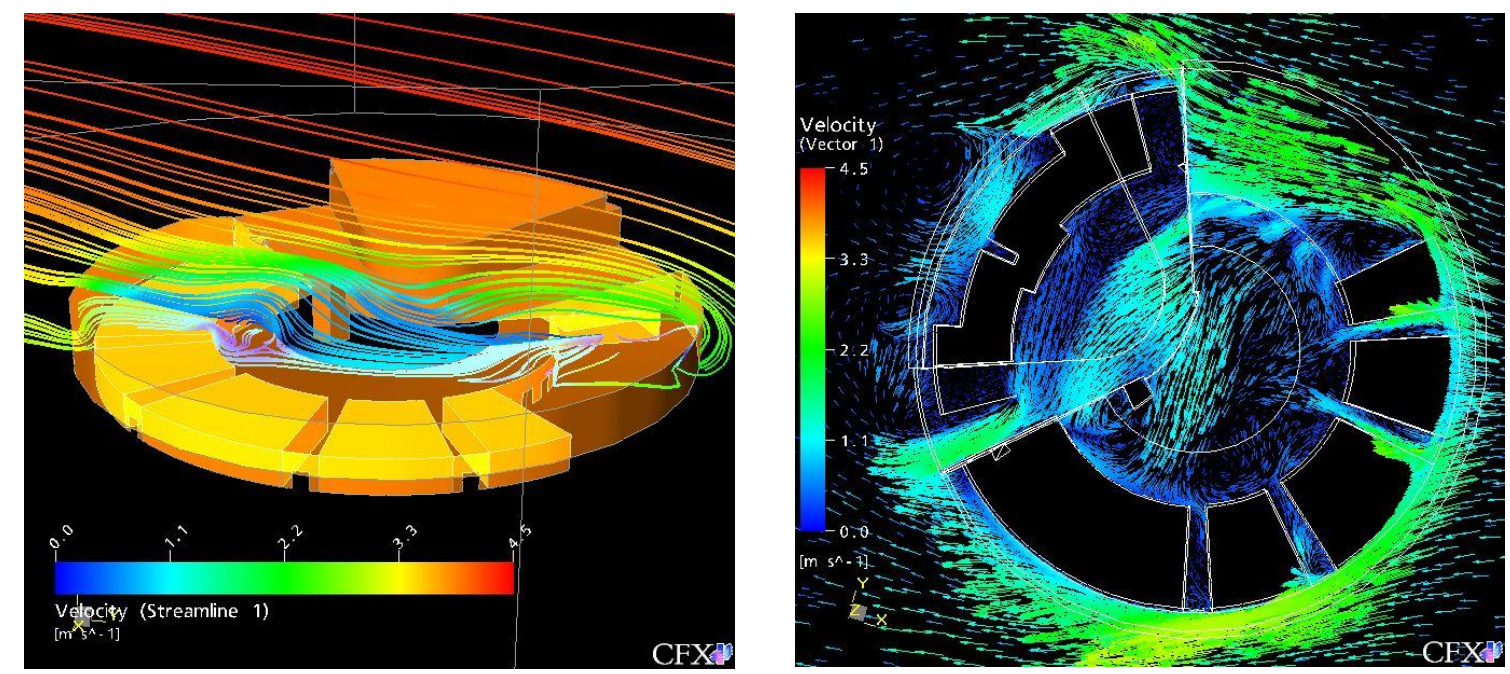

Figura 22 - Resultados para simulação de ventilação no Centro de Convenções: streamline e campo de velocidades a $1,5 \mathrm{~m}$

Em função dos resultados, considerou-se uma velocidade do ar de $0,8 \mathrm{~m} / \mathrm{s}$, aumentando assim a porcentagem das horas de conforto. No caso do salão de eventos, esta pode ser considerada uma abordagem conservadora, já que as velocidades encontradas estão próximas de $2,0 \mathrm{~m} / \mathrm{s}$. Também foi considerada uma parede dupla de concreto na 
face externa do restaurante, reduzindo os ganhos de calor.

Como resultado o período em conforto para o restaurante foi elevado para $51 \%$ do tempo de ocupação. Esse número está muito próximo do valor encontrado no item 2.2.3. Em junho e julho, esse valor chega a $94 \%$ do tempo de ocupação, indicando que o potencial para condicionamento natural foi atingido.

No caso da área de eventos, a membrana dupla reduziu os ganhos solares e a temperatura superficial da face interna da cobertura, com um acréscimo das horas em conforto de $13 \%$ para $35 \%$, considerando-se um PPD de $10 \%$. Assumindo-se um PPD de 20\%, obteve-se um cenário com $60 \%$ das horas do ano em conforto. Isso indica que, durante a maior parte do tempo, as temperaturas efetivas obtidas não estão distantes dos limites estabelecidos, já que uma leve extensão da zona de conforto leva à duplicação do período confortável. O resultado final foi considerado satisfatório para um espaço ventilado naturalmente, considerando-se a flexibilidade do uso e a função.

\section{Considerações finais}

Considerando-se as condições climáticas locais, os resultados de desempenho térmico nos ambientes com ventilação natural mostram a adequação arquitetônica ao clima.

A tipologia do edifício industrial teve um papel decisivo no desempenho das estratégias passivas, incluindo o pé-direito duplo e triplo, os fechamentos verticais com poucas aberturas e a cobertura em shed, que favoreceram a ventilação natural por efeito chaminé e o acesso da luz natural difusa. Sombreamento e ventilação natural foram as principais estratégias nesses edifícios, às quais se somam o isolamento térmico para o exterior e a inércia térmica no interior dos ambientes. No caso dos ambientes internos com elevada carga térmica a ventilação mecânica teve que ser introduzida, devido ao calor latente, principalmente de dezembro a fevereiro.

O melhor desempenho dos ambientes naturalmente ventilados foi encontrado no restaurante do Centro de Convenções, com $70 \%$ das horas de ocupação do ano dentro da zona de conforto, enquanto o percentual mais baixo foi na cozinha da Empreiteirópolis, com 51\%, com PPD de 20\%.

Para o ar condicionado, foram propostos parâmetros não usuais de operação visando à eficiência energética dentro dos limites do conforto. No projeto final, todas as áreas em que o ar condicionado se mostrou necessário em algum período do ano foram consideradas totalmente condicionadas artificialmente, devido a razões técnicas, econômicas e, principalmente, culturais.

Tanto nos gabinetes dos Laboratórios como nos ambientes de trabalho do Prédio Central a estratégia de modo-misto foi descartada devido à não aceitação da mudança de estratégia de climatização por parte dos ocupantes. Contudo, com o projeto de janelas operáveis e o zoneamento da distribuição de ar (um fan-coil para cada unidade de laboratório), a opção de ventilação natural é dada aos usuários.

No Prédio Central, apesar dos estudos realizados, algumas características arquitetônicas, como piso elevado e forro rebaixado, resultaram em ambientes internos similares àqueles da cultura internacional do ambiente de trabalho. Já os gabinetes dos Laboratórios, com dimensões reduzidas e cargas térmicas relativamente baixas, além da massa térmica interna, apresentaram desempenho relativamente melhor, principalmente pela ventilação natural.

Concluindo, a experiência de projeto e da avaliação de desempenho ambiental desse trabalho foi pautada em uma abordagem contemporânea do processo de projeto na prática brasileira, com resultados bastante satisfatórios, tendo em vista o rigor das condições ambientais locais.

\section{Referencias bibliográficas}

\section{ASSOCIAÇÃO BRASILEIRA DE NORMAS}

TÉCNICAS. NBR 6401: instalações centrais de ar-condicionado para conforto: parâmetros básicos de projeto. Rio de Janeiro, 1980.

AGÊNCIA NACIONAL DE VIGILÂNCIA SANITÁRIA. Orientação Técnica sobre Padrões Referenciais de Qualidade do Ar Interior, em Ambientes Climatizados Artificialmente de uso Público e Coletivo. Brasília, 2003. (Resolução RE9).

AMERICAN SOCIETY OF HEATING, REFRIGERATING AND AIR CONDITIONING ENGINEERS. ASHRAE 55-1992: thermal environmental conditions for human occupancy. Atlanta, 1992.

\section{AMERICAN SOCIETY OF HEATING, REFRIGERATING AND AIR CONDITIONING ENGINEERS. ASHRAE 55-2004: thermal} environmental conditions for human occupancy. Atlanta, 2004. 
CRAWLEY, Drury. Curso Avançado em "Energy Plus". Compilado por Serviço de Comunicação Social da Escola Politécnica da Universidade de São Paulo. Abril de 2008. (Notas de aula).

DE DEAR, Richard; BRAGER, G.; COOPER, D. Developing an Adaptive Model of Thermal Comfort and preference. Final Report, ASHRAE RP-884, Macquire University, 1997.

FANGER, P. O. Thermal Comfort. Nova York: McGraw-Hill, 1970.

GONÇALVES, Joana Carla Soares. A Sustentabilidade do Edifício Alto: uma nova geração de edifícios altos e sua inserção urbana. 2003. (Tese de doutorado em Arquitetura) Universidade de São Paulo, Faculdade de Arquitetura e Urbanismo, São Paulo, 2003.

HOPPE, Peter. Different Aspects of Assessing Indoor and Outdoor Thermal Comfort. Energy and Buildings, Munique, v. 34, n. 6, p. 661-665, jul. 2002.

\section{INTERNATIONAL ORGANIZATION} STANDARDIZATION. ISO 7726: ergonomics of the thermal environment: instruments for measuring physical quantities. Genebra, 1998.

\section{INTERNATIONAL ORGANIZATION}

STANDARDIZATION. ISO 8996: ergonomics: determination of metabolic heat production. Genebra, 1990.

\section{INTERNATIONAL ORGANIZATION} STANDARDIZATION. ISO 7730: moderate thermal environments: determination of the PMV and PPD indices and specification of the conditions for thermal comfort. Genebra, 1994.
INTERNATIONAL ORGANIZATION

STANDARDIZATION. ISO 9920: ergonomics of the thermal environment: estimation of the thermal insulation and evaporative resistance of a clothing ensemble. Genebra, 1995.

METAR. Dados Climáticos do Aeroporto do Galeão 1998-2004. São Paulo: Instituto de Astronomia, Geofísica e Ciências Atmosféricas da Universidade de São Paulo, 2005.

METEOTEST. Meteonorm 5.0. Switzerland: the swiss federal office of energy. Suiça, 2003.

\section{BRASIL. MINISTÉRIO DO TRABALHO. NR} 15: atividades e operações insalubres, anexo 3 : limites e tolerância para exposição ao calor. Brasília, 1978.

\section{BRASIL. MINISTÉRIO DO TRABALHO. NR} 17: ergonomia e segurança do trabalho. Brasília, 1973.

SZOKOLAY, S. Use of the New Effective Temperature. ET* in Practice. In: F. Pererra, PLEA 2001. In: CONFERENCE ON PASSIVE AND LOW ENERGY ARCHITECTURE, 18., Florianópolis. Anais... Florianópolis, 2001. p. 1003-1007.

UK Legislations. Building Regulations 2000. The stationery office limited. Londres, 2000.

\section{Agradecimentos}

Ao Eng. Fúlvio Vittorino, do Instituto de Pesquisas Tecnológicas do Estado de São Paulo (IPT), a Klaus Bode e Allan Harries, do BDSP Partnership, Londres. À Siegbert Zanettini e Érika Bataglia e à Petrobras, pela autorização da publicação das informações apresentadas nesse artigo. 